\title{
Neurological Manifestation of SARS-CoV-2 Induced Inflammation and Possible Therapeutic Strategies Against COVID-19
}

\author{
Dipak Kumar ${ }^{1}$ (D) Sadaf $\operatorname{Jahan}^{2}$ (D) - Andleeb $\mathrm{Khan}^{3}$ (D) $\cdot$ Arif Jamal Siddiqui $^{4}$ (D) Neeru Singh Redhu ${ }^{5}$ (D) \\ Wahajuddin $^{6}$ (1) $\cdot$ Johra Khan $^{2} \cdot$ Saeed Banwas ${ }^{2,7,8} \cdot$ Bader Alshehri $^{2,7} \cdot$ Mohammed Alaidarous $^{2,7}$
}

Received: 3 September 2020 / Accepted: 1 February 2021 / Published online: 14 March 2021

(C) The Author(s), under exclusive licence to Springer Science+Business Media, LLC, part of Springer Nature 2021

\begin{abstract}
There are regular reports of extrapulmonary infections and manifestations related to the ongoing COVID-19 pandemic. Coronaviruses are potentially neurotropic, which renders neuronal tissue vulnerable to infection, especially in elderly individuals or in those with neuro-comorbid conditions. Complaints of ageusia, anosmia, myalgia, and headache; reports of diseases such as stroke, encephalopathy, seizure, and encephalitis; and loss of consciousness in patients with COVID-19 confirm the neuropathophysiological aspect of this disease. The brain is linked to pulmonary organs, physiologically through blood circulation, and functionally through the nervous system. The interdependence of these vital organs may further aggravate the pathophysiological aspects of COVID-19. The induction of a cytokine storm in systemic circulation can trigger a neuroinflammatory cascade, which can subsequently compromise the blood-brain barrier and activate microglia- and astrocyte-borne Toll-like receptors, thereby leading to neuronal tissue damage. Hence, a holistic approach should be adopted by healthcare professionals while treating COVID-19 patients with a history of neurodegenerative disorders, neuropsychological complications, or any other neuro-compromised conditions. Imperatively, vaccines are being developed at top priority to contain the spread of the severe acute respiratory syndrome coronavirus 2 , and different vaccines are at different stages of development globally. This review discusses the concerns regarding the neuronal complications of COVID-19 and the possible mechanisms of amelioration.
\end{abstract}

Keywords COVID-19 $\cdot$ Neuropathophysiology $\cdot$ Cytokine storm $\cdot$ Neurodegenerative disorders $\cdot$ Vaccine $\cdot$ Pandemic

\section{Introduction}

The severe acute respiratory syndrome (SARS), a disease in consideration, is described by an acute pyretic response triggered primarily owing to pulmonary tissue infection. A high proportion of affected hospitalized patients die due to respiratory collapse $[1,2]$. However, the severe acute respiratory

Dipak Kumar and Sadaf Jahan contributed equally to this work.

Sadaf Jahan

jahan149@gmail.com; s.jahan@mu.edu.sa

1 Zoology Department, KKM College, Jamui, Munger University, Munger, India

2 Department of Medical Laboratories, College of Applied Medical Sciences, Majmaah University, Majmaah 11952, Saudi Arabia, Kingdom of Saudi Arabia

3 Department of Pharmacology and Toxicology, College of Pharmacy, Jazan University, Jazan 45142, Saudi Arabia syndrome coronavirus 2 (SARS-CoV-2), which has been implicated as the causative agent in the ongoing pandemic, does not remain confined to the lungs, as suggested by various observations. Extrapulmonary manifestations reported among patients are myocardial dysfunction, thrombotic complications, and arrhythmia, thrombocytopenia, lymphocytopenia, acute kidney injuries and acute coronary syndromes,

4 Department of Biology, College of Science, University of Hail, Hail, PO Box 2440, Saudi Arabia

5 Department of Molecular Biology, Biotechnology and Bioinformatics, Chaudhary Charan Singh Haryana Agricultural University, Hisar, Haryana 125004, India

6 Division of Pharmaceutics \& Pharmacokinetics, CSIR-Central Drug Research Institute, Lucknow, UP, India

7 Health and Basic Sciences Research Center, Majmaah University, Majmaah 11952, Saudi Arabia

8 Departments of Biomedical Sciences, Oregon State University, Corvallis, OR 97331, USA 
gastrointestinal symptoms such as diarrhea, hepatic injuries, low sugar level, and ketosis, along with neuronal disorders, dermatologic issues, and ocular disturbances [3, 4].

The coronavirus $(\mathrm{CoV})$ particle comprises four structural components: S (spike) protein, $\mathrm{M}$ (membrane) protein, $\mathrm{E}$ (envelope) protein, and $\mathrm{N}$ (nucleocapsid), which are essential for its assembly and infectivity. The spike present on the viral surface consists of homotrimers of S proteins that are responsible for mediating CoV entry to the host cell. The entry is achieved through the contract between the spike protein and plasma membrane receptor of the host cell, which subsequently leads to catalysis, the virus-cell membrane fusion, and the release of viral content into the host cell. The M protein, comprising three transmembrane domains, provides structure to the virion, supports membrane curvature, and binds to the nucleocapsid. The $\mathrm{N}$ protein has two domains; both domains bind to the RNA genome of the virus and help viral replication. Viral assembly is governed by the E protein, which is also responsible for pathogenesis [5].

Until 2019 end, only six CoVs were reported that could infect humans and cause respiratory distresses. Now, we have the seventh $\mathrm{CoV}$ as SARS-CoV-2 whose couple of strains have been reported from the UK and Africa in the year of 2020. The majority of them (four out of six CoVs) could cause only mild upper respiratory symptoms and would rarely lead to severe infection in infants, adolescents, or the elderly. The other two, named severe acute respiratory syndrome coronavirus (SARS-CoV) and Middle East respiratory syndrome coronavirus (MERS-CoV), were associated with severe respiratory syndrome among humans [6, 7]. Before infecting neural cells, CoV particles can access several routes, including through leukocyte migration across the blood-brain barrier (BBB), vascular epithelial infection, transsynaptic transfer through infected neurons, or via the olfactory nerve [8]. However, the chances of direct endocytic infection, as established for the Zika virus and Tick-borne encephalitis virus, cannot be overruled. CoVs were predominantly found to infect neurons, besides eliciting cardiac and respiratory control in the brain stem, injuries to which may aggravate or even lead to respiratory collapse [9].

Further, it is well known that primary receptor angiotensin-converting enzyme 2 (ACE2), which is a metallopeptidase, and transmembrane serine protease 2 (TRPMSS2), which is an endoprotease, form a cell surface complex and collectively operate as a portico for glycoprotein activation for SARS-CoV entry into host cells [10]. The proteins are expressed in the olfactory epithelium located close to olfactory sensory neurons along with other organ tissues, which include pulmonary tissues, renal, enterocytes, and prostate glands among others [11]. The putative expression and location of ACE2 and TRPMSS2 in the olfactory bulb suggests the strong neurotropism of SARS-CoV-2, as observed in previously reported $\mathrm{CoVs}$
[12]. Both upper airway epithelium and vascular epithelium express ACE2 at abundant levels, which can facilitate the entry of the virus into cells of the central nervous system (CNS). As neural cells, including neurons and neuroglia, express ACE2, CoVs can infect these as well. Once it enters the CNS, it can further disseminate using axodendritic transsynaptic tracks. For instance, in a rodent model, intranasal SARS-CoV-1 exhibited tropism toward the cerebral, thalamus, and rhombencephalon derivatives, as expected in the case of viral encephalitis [13].

Recently, chronic neuroinflammation is associated with the neuropathophysiological aspects of certain neurodegenerative diseases (NDDs) such as multiple sclerosis (MS), Parkinson's disease (PD), and Alzheimer's disease (AD), among others $[14,15]$. In the case of $\mathrm{AD}$, the microglia lose the ability to phagocytize the $\mathrm{A} \beta$ protein in the presence of pro-inflammatory cytokines or chemokines, which favors the deposition of pathogenic $A \beta$ plagues [16]. Similarly, there are pathophysiological evidence observed in other NDDs. The cytokine storm (CS) induced as a result of SARS-CoV-2 infection involves the neuroinflammatory cascade activation, similar to that observed in NDDs. Furthermore, there is a possibility that this molecular alteration may persist even after the acute infection is eliminated, owing to which the health of the CNS remains sustainably compromised. Lastly, it remains unknown whether SARS-CoV-2 has the ability to remain in a latent state in the CNS like other CoVs, which may increase the possibility of sustained neuroinflammation and compromised neural functions. In this review, we discuss the neuropathophysiological complications, the mode of SARS-CoV-2 infection in the CNS, and the possible mechanisms of amelioration of neuro-comorbid conditions.

\section{SARS-COV-2 INFECTION IN THE CNS}

COVID-19 (coronavirus disease) is characterized by various neurological symptoms, necrotizing hemorrhagic encephalopathy, including encephalitis, encephalopathy, Guillain-Barre syndrome, epileptic seizures, stroke, and rhabdomyolysis, among several others [17]. Other reported neurologic symptoms, such as compromised consciousness and hallucination, indicate SARS-CoV-2 entry and infection in the neocortex of the CNS [18]. Recently, SARS-CoV-2 has been detected in the frontal lobe tissue of a patient in transmission electron microscopy experiments [8]. Based on the above observation, it can be suggested that SARS-CoV-2 prefers a hematogenous route to enter into CNS.

The neuronal complications observed in $36.4 \%$ of patients with COVID-19 in Wuhan, China, as reported in a retrospective study on 214 subjects [19], have been cited in several 
recent studies. In these patients, symptoms such as headache and distressed consciousness confirmed the neuronal involvement in the disease. Besides, both ischemic and hemorrhagic strokes were reported in six patients, and "muscle injury" characterized by elevated creatine kinase levels was observed in twenty-three patients [20]. The authors of the concerned study hypothesized that this might be associated with elevated D-dimer levels. Such observations in the patients of ICU lead them to a hypercoagulable state. Some of the major signs of the neurological establishment of COVID-19-related encephalitis were reported in Beijing, China [21]. In addition to convulsions and persistent hiccups, there were several neurological complications, such as slow pupillary response, meningeal irritation, and bilateral ankle clonus that were observed upon examination.

Another fundamental aspect of SARS-CoV-2 infection in the CNS is the induction of high levels of systemic inflammation with a substantial release of cytokines, chemokines, and other inflammatory signals, which constitute CS [22] which subsequently leads to a significant disruption of the BBB, along with the initiation and exacerbation of neuroinflammation. It has been consistently demonstrated in clinical and preclinical studies that systemic inflammation induced by bacteria, virus, or any toxic agent compromises the BBB, activates microglia- and astrocyte-borne Toll-like receptors, and damages the glia limitans [23], which are associated with innate immunity [24]. This eventually promotes neuroinflammation, which substantially disrupts brain homeostasis and leads to neuronal apoptosis [25].

Hence, functional brain damage resulting from neuroinflammation could explain the clinical experience with respect to the onset or progression of behavior-associated cognitive impairments in the patients who have overcome pneumonia [26]. Neurobehavioral abnormalities such as delirium and cognitive deficits are observed frequently under conditions of systemic inflammation resulting from prolonged hypoxia and the subsequent induction of persistent and uncontrolled neuroinflammation [27]. Consequently, the condition leads to the damage of the hippocampus and cortical areas, which govern cognitive functions and neurobehavioral fluctuations [28]. Hence, CNS infection accompanied by systemic inflammation in patients with COVID-19 leads to the loss of integrity in the BBB and initiates a strong neuroinflammatory response characterized by reactive astrogliosis and microglial activation [29]. Moreover, neuropsychiatric progression and cognitive impairments, both acute and chronic, can be triggered by neuroinflammation in conjunction with prolonged hypoxia [30]. Therefore, the neurological and neuropsychiatric aspects of neuroinflammation, along with pulmonary amelioration, must be considered while designing the therapeutic schemes and rehabilitation schedule for patients with COVID-19 [31].

\section{POSSIBLE NEUROINVASIVE PATHWAYS OF SARS-COV-2 INFECTION}

Accumulating shreds of evidence suggest that the severity of COVID-19 correlates with the increased frequency of neurological complications [32, 33]. For instance, the association between meningitis/encephalitis accompanying significant paranasal sinusitis in patients with COVID-19 was reported in a study [34]. Further, sinusitis can be linked with viral infection exacerbated by an obstruction in the paranasal lymph vessels. The presence of a brain-wide glymphatic pathway that requires the involvement of olfactory or cervical lymph vessels is a notable characteristic feature [35]. The brainthrough connection can allow the direct entry of SARSCoV-2 into brain cells. Apart from such possibilities, there are definitive routes of $\mathrm{CoV}$ entry into the brain, such as across perforations in the ethmoid bone and through the compromised BBB [36]. The transmission of $\mathrm{CoV}$ from systemic circulation or through the cibriform plate of the ethmoid bone at different phases of viral infection has been reported to have cerebral involvement in patients with $\mathrm{CoV}$ infections. Based on recent observations and reports, two routes of SARS-CoV2 entry into the CNS have been discussed here.

\section{Transcribrial RouteTranscribrial Route}

The perforations in the cribriform plate of the ethmoid bone allow passage of the axons from olfactory sensory neurons. The axons form synapses at the glomeruli with the dendrites of the mitral cells in the area of the olfactory bulb, which communicates with the brain through the olfactory tract (Fig. 1(a)). Anosmia and ageusia that have been reported in several cases of COVID-19 are directly related to the involvement of the olfactory sensory system. As indicated, these neurons express ACE2, which SARS-CoV-2 binds to, and travel retrograde using transsynaptic vesicles to access the brain [37]. Alternatively, the virus can potentially travel along the olfactory nerve without entering the neuron cytoplasm. This route of invasion was established when transgenic mice that express ACE2 were infected with SARS-CoV-1 and MRSCoV intranasally [38].

The binding affinity of the SARS-CoV-2 spike protein ectodomain with ACE2 was reported to be 10- to 20-fold higher than that of the spike protein ectodomain of SARSCoV-1 [39]. Hence, the perforations in the cribriform plate can act as a definitive route for the virus to infect and affect the CNS [40]. In the vicinity of neuronal cells, the interaction of $\mathrm{CoV}$ and ACE2 receptors can trigger a cycle of budding viral phenomena that causes neuronal damage without noticeable inflammation, as previously observed in cases of SARSCoV [41]. The virus can adopt fast axonal transport using axonal microtubules, which involves either retrograde or anterograde movement of molecules, to spread within the 


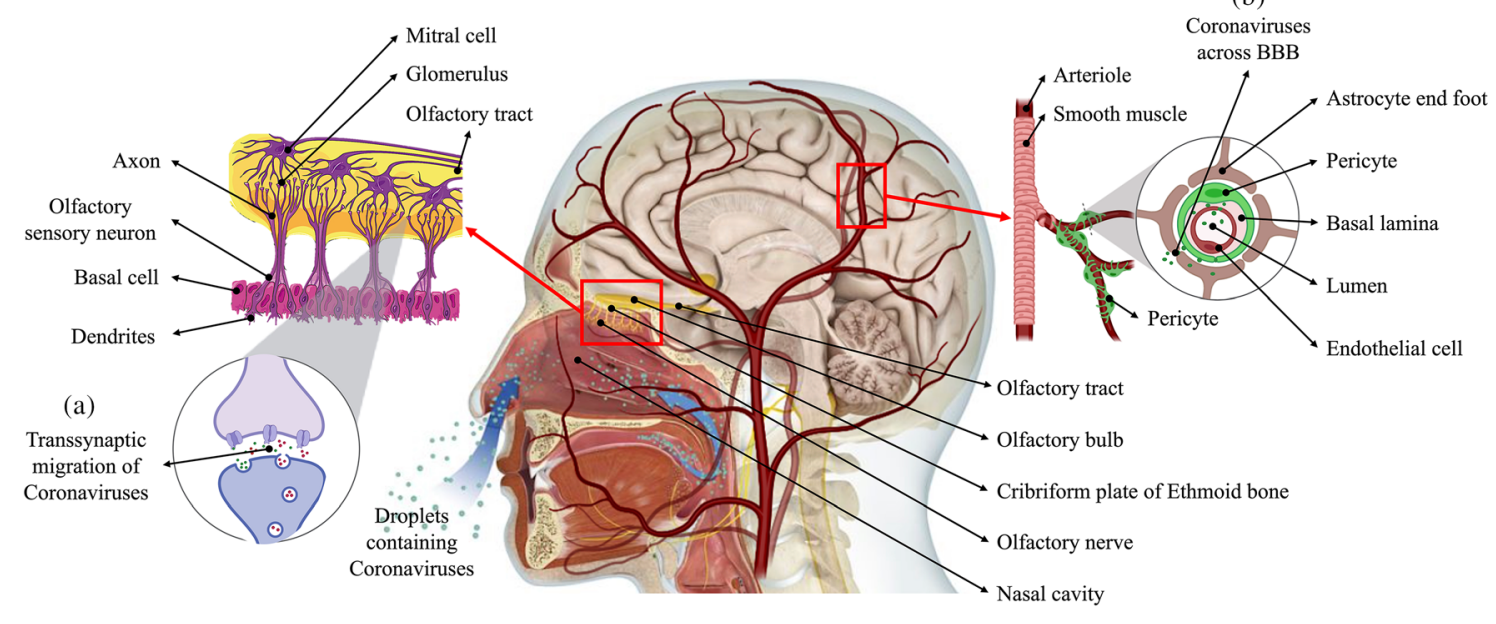

Fig. 1 Demonstration of neurotropism. Coronavirus in the nasal cavity can directly cross the transcribrial opening in the ethmoid bone to access the brain or perform (a) transsynaptic retrograde migration using the vesicle transport machinery used by neurotransmitters. (b) In blood

circulation, the virus can infect vascular endothelial cells, which further provide access to the glial cells of CNS; alternatively, virally infected leukocytes can transport the virus across the BBB and facilitate the infection of the CNS

neuron. Certain viruses, such as herpes simplex virus (HSV) and human immunodeficiency virus (HIV), have been reported to utilize the rearward fast axonal transport for entering the neuronal body [42].

\section{Hematogenous Route}

The formation of the BBB involves coordination among neurons, astrocytes, pericytes, vascular smooth muscle cells, and endothelial cells for regulating the regional cerebral blood flow, as required for optimal neuronal activities [43]. Essential macromolecules are transported through this barrier into the CNS by selective transcytosis while maintaining neurovascular coupling and hemodynamic responses to support the demands of neuronal physiological activities. The membrane also maintains the extracellular fluid in the CNS while preventing the hematogenous entry of neurotoxic compounds and microbial agents into the brain. Endothelial cells express ACE2, which makes them susceptible to SARS-CoV2 infection, which can potentially lead to the deterioration of the integral architecture of the BBB [44]. The resulting hypoperfusion can restrict the entry of molecules that are necessary to maintain neuronal structure and functions, thus promote the cognitive impairment in the affected individuals.

Viruses in the blood circulation possibly bind to ACE2 expressed on vascular endothelial cells, which enables them to infect and further move into the cerebral circulation (Fig. 1(b)). The tight junctions between vascular endothelial cells may serve as another point of entry into the cerebral circulation, as the leisurely motion of the blood in the capillaries could be one of the factors that aid the interaction of the viral spike protein with ACE2 expressed in the surrounding cells. There are pieces of evidence of the infection of vascular endothelial cells and the transport of $\mathrm{CoV}$ through this route, as shown in an autopsy study wherein SARS-CoV-2 was observed in a section of the frontal lobe specimen [8]. Vesicles in the neurons of the frontal lobe were observed to be dilated in the presence of viral particles. Additionally, electron microscopy has also revealed the process of endocytosis and exocytosis being used by the viral particles to move across vascular endothelial cells [45]. Hence, the resulting disruptions of the neurovascular unit can create a potential pathway for viral entry into the CNS and cause localized inflammatory and immune responses that initiate neurodegenerative processes. The viral particle budding from endothelium leads to the damage in the endothelial lining and facilitates the viral entry to the brain [46].

\section{NEUROLOGICAL COMPLICATIONS ALONG WITH SARS-COV-2 INFECTION}

Impaired neurovascular coupling, diminished cerebral blood flow, and in limbic and associative cortices are associated with aging. The disruption of the BBB in the older adults increases their susceptibility to neuro-invasion during infection of SARS-CoV-2. The long-term consequences of the disease are associated with aging and age-related neurodegenerative disorders. The aggravation of neuropathological conditions upon viral infection causes an acceleration in the onset or further deterioration of existing motor and cognitive deficits. Once the current viral outbreak is managed, our healthcare system could be faced with a high number of patients dealing with the abovementioned conditions and analogous comorbid neurological problems. Accordingly, long-term neuronal problem follow-ups in aged population adults may be necessary post-severe COVID-19 infection. Keeping these 
considerations in mind, the following neuronal disorders are being discussed here.

\section{Alzheimer's disease and related dementias (ADRD)}

Under normal conditions, patients with ADRD needs special care and are more prone to infections or diseases. Under the ongoing COVID-19 pandemic, the vulnerability of these patients has increased directly owing to the rise in morbidity and mortality and indirectly owing to significant changes in the healthcare system, on which they are heavily dependent. The draconian implications of this situation are not restricted to patients with dementia who are infected by the virus, noninfected patients are also susceptible, as the restriction on free movement and meeting with family and friends exacerbates the severity.

Alzheimer's disease (AD) patients are at higher risk of contracting SARS-CoV-19 infection [47]. The general recommendations for the prevention of SARS-CoV-2 infection provided by public health authorities, such as hygiene of the hands, mouth, and nose; maintenance of physical distance; or public isolation, cannot be followed by AD patients. Owing to dementia, they may be unable to remember or understand the directions or precautions that are necessary under the ongoing pandemic. If conditions such as depression, apathy, and restricted mobility are accompanied by the general symptoms, it becomes significantly difficult for them to comply with the safety rules. Patients with severe AD who have psychological and behavioral symptoms of dementia are considerably restless to be able to remain in isolation [48]. Confinement and isolation during the COVID-19 lockdown led to the exaggeration of neuropsychiatric symptoms in patients with $\mathrm{AD}$ [49]. The care of elderly patients with $\mathrm{AD}$ and related dementia who have multiple comorbidities and test positive for COVID-19 would be a major challenge for caregivers and hospital staff [50].

The risk factors of $\mathrm{AD}$ and related dementia viz. age, cardiovascular diseases, type 2 diabetes, and obesity are major risk factors for COVID-19 as well, which makes such individuals more vulnerable to SARS-CoV-2 [51]. A report stated in Italy that almost one-third of the confirmed cases and approximately 9 of 10 deaths were reported in people above 70 years of age [52]. It is known that among people of the same age, those with dementia are more likely to develop cardiovascular disease, pneumonia, and diabetes than those without dementia [53]. These conditions are also associated with susceptibility to SARS-CoV-2 infection [54]. Guan et al. suggested that out of the confirmed cases reported in China until April 2020, patients in more than $90 \%$ of the cases presented with pneumonia [55]. Foley et al. stated that the rate of mortality in patients with pneumonia was two times higher if the patient had dementia than if they did not [56].
The pandemic exerted an adverse effect on the global healthcare system. The functional hospitals and clinics have been converted to deal with the current crisis, and pre-booked appointments with patients have been extended until further notice. There have been reports of the diversion of health resources from patients with ADRD [57]. With respect to the medications required for treating $\mathrm{ADRD}$, anticholinesterase inhibitors are used most commonly to stabilize the patients; therefore, the non-availability of the drug could affect the patients. This could be attributed to missed visits or delay in supply from the pharmaceutical organizations during the pandemic. Patients with ADRD already face significant social stigma [58], and individuals with or at risk of contracting COVID-19 have been stigmatized as well. Therefore, patients with ADRD who are at risk of contracting COVID-19 have considerably higher chances of facing social stigma and mental stress [59].

The major risk factor for COVID-19 in patients with AD is the APOE e4 allele. The APOE e4 genotype is commonly associated with a 14-fold increase in the risk of $\mathrm{AD}$ [60]. Kuo et al. reported that the APOE e4 genotype could predict the risk for severe COVID-19 among individuals of the UK Biobank community [61]. It was stated that the APOE e4 allele increases the risk of COVID-19 regardless of the history of dementia. The gene is highly co-expressed with ACE2, which has been discussed above in detail. Further investigation on the co-expression of the two genes is necessary. Patients with dementia presenting with clinical symptoms of COVID-19 is an atypical observation, which delays early diagnosis and treatment. The worsening status of dementia should be considered a symptom of COVID-19 in such patients. This can lead to early recognition, isolation, and timely treatment of such subjects [62].

With an increase in age, the inflammation increases, and a special term "inflammaging" is coined for this process. A higher current baseline of inflammation may be one of the reasons why older individuals are at a higher risk of infection [63]. COVID-19 has been known to link with "cytokine storm" which results in increase of pro-inflammatory cytokines (TNF- $\alpha$, IL-1, IL-6, IL-1 $\beta$ ), which have been reported to increase in aged people $[63,64]$. Therefore, it makes the elderly especially vulnerable to extreme COVID-19 conditions. In addition to the overlapping pathology of type 2 diabetes and $\mathrm{AD}$, the potential for elevations in blood glucose to increase inflammation through interferon regulatory factor 5 (IRF5) activity may produce a "perfect storm" of excessive immune response after SARS-CoV-2 infection in AD patients [65]. As a result, immunosenescence, neuroinflammation, and neurodegeneration are observed in the patients with $\mathrm{AD}$, leading to dysfunction of microglia accumulating amyloid-beta and consequently loss of peripheral immune response [66].

Another hypothesis for COVID-19 severity in AD patients is the involvement of interferons (IFN). In response to viral 
infections, IFNs are produced by the host body. IFNs also have a role in AD pathology, thereby indicating nucleic acid containing amyloid fibrils stimulating the expression of genes responsible for IFN production. Microglia are activated by IFN, which gets associated with the nucleic acid containing amyloid plaques, stimulating a pro-inflammatory response. IFN further activates complement cascade and leads to synapse degeneration [65].

The association of COVID-19 is also reported with the enhanced pro-coagulation factors like fibrinogen, blood clotting time, and the D-dimer level, which imparts its role in the increased mortality of patients by halting pulmonary normal function. COVID-19 can also cause the stimulation of mast cells, which results in the cytokine storm in the lungs. It is also reported that mast cells are associated with the stressinduced stroke. Therefore, in SARS-COV-2 infection, via mast cell activation, the severity of the condition is observed in lungs as well as in the brain. Mast cells are responsible for the instant secretion of proteases like CXCL10, GM-CSF, CCL2, TNF- $\alpha$, tryptase, and chymase, and inflammatory factors such as LTC4, PGD2, CRH, IL33, CCL2, VEGF, and histamine. This condition is also a source for creating oxidative stress, which is directly associated with enhanced apoptotic activity in cells, enhanced reactive species (ROS, NO), and dysfunctional mitochondria (MMP3). Some recent studies indicate the involvement of Toll-like receptors (TLRs) in the activation of mast cells [67] which can lead to the release of CD40, CD40L, CD88, PAR2, UCP2\&4, $\mathrm{Ca}^{2+}$, LPS, MAPK, and NF-kB from glial cell further affecting neuron integrity. The diagrammatic representation of immunological crosstalk between infected lungs and the brain, and possible neurodegenerative amelioration due to COVID-19 infection is depicted in Fig. 2.

\section{Parkinson's Disease and Parkinsonism}

Parkinson's disease (PD) and Parkinsonism are comorbidities similar to AD that are associated with COVID-19. Patients with PD and those with COVID-19 share characteristics such as age and risk of respiratory problems. This puts patients with PD at a potential risk of contracting COVID-19 [68]. The death of a 77-year-old Korean man with PD dementia due to COVID-19 with respiratory failure was reported [68]. Comorbidities like age, cardiovascular diseases, and diabetes are identified risk factors for PD as well as for COVID-19 [69, 70]. The nuclei in the brainstem, which is the respiratory centers in the medulla, are affected during the early stage of PD neurodegeneration and are also targeted by SARS-CoV-2 [71]. Parkinsonism has the main histological feature of intracellular Lewy body deposition (misfolded $\alpha$-synuclein protein aggregates) [72]. The suggested mechanisms of PD onset and progression are oxidative stress, neuroinflammation, calcium homeostasis alteration, apoptosis, mitochondrial dysfunction, and synaptic pathogenesis [72]. Meng and colleagues reported that infections could lead to PD development [73]. Lewy body deposition is reported to be at the brainstem and olfactory lobe than substantia nigra, and we have already discussed that virus can reach both the brainstem and olfactory cortex via the transsynaptic route and olfactory epithelium. Once inside, the virus has the tendency to trigger the immune response leading to neuroinflammation [74]. Recent evidence indicates that $\alpha$-synuclein can partake in the immune response and can provoke its upregulation [75]. Activation of microglia produces cytokines and chemokines escalating further the immune response causing neuronal degeneration $[76,77]$.

Pneumonia is one of the primary causes of morbidity and mortality in patients with PD $[68,78]$. Bhidyasiri et al. hypothesized that mastication and swallowing are impaired in PD progression, which leads to saliva accumulation in the oral cavity and to aspiration of salivary secretion $[68,79,80]$. With further advancement of PD, the cough reflex is inhibited owing to chest wall rigidity, which leads to aspiration pneumonia. This could form the most conducive environment for SARS-CoV-2 infection in case the patient is exposed. Patients with PD are immunocompromised, which makes them more susceptible to SARS-CoV-2 infection [81]. As $\mathrm{PD}$ is an age-related disorder, immunosenescence is common in patients. Adaptive immunity is compromised in such patients, and there is non-specific tissue inflammation, which makes them highly susceptible to COVID-19 [68, 82]. High fever, a common symptom in COVID-19, could exacerbate Parkinsonism in PD patients with COVID-19 [55]. Moreover, the dopamine imbalance in patients with PD could lead to an inflammatory response, or toxin or cytokine activation [83]. Therefore, patients with PD should be carefully monitored for motor function disabilities and extended in the resuscitation period.

Another hypothesis proposed by Pavel and colleagues is that $\alpha$-synuclein can act as an antiviral agent in neurons [84]. As a consequence of SARS-CoV-2 infection like the H5N1 influenza virus, a peripheral inflammatory response occurs along with abnormal $\alpha$-synuclein phosphorylation in substantia nigra pars compacta dopaminergic neurons [85]. They postulated that following COVID-19 infection, antiviral $\alpha$-synuclein accumulation might make up preexisting cell-autonomous vulnerabilities, causing neurodegeneration [84]. They also hypothesized that $\alpha$-synuclein clearance is also affected by SARS-CoV-2 infection by binding to ORF8, human protein trafficking molecule which impairs proteostasis and causes uncontrollable aggregation of $\alpha$-synuclein [84]. There are numerous indirect effects of COVID-19 on patients with PD, which represent altered symptoms and activities and stress on the patients [86]. Complete/partial lockdown limits movement and social distancing keeps them separated from acquaintances and relatives. This exacerbates depression, mental stress, 


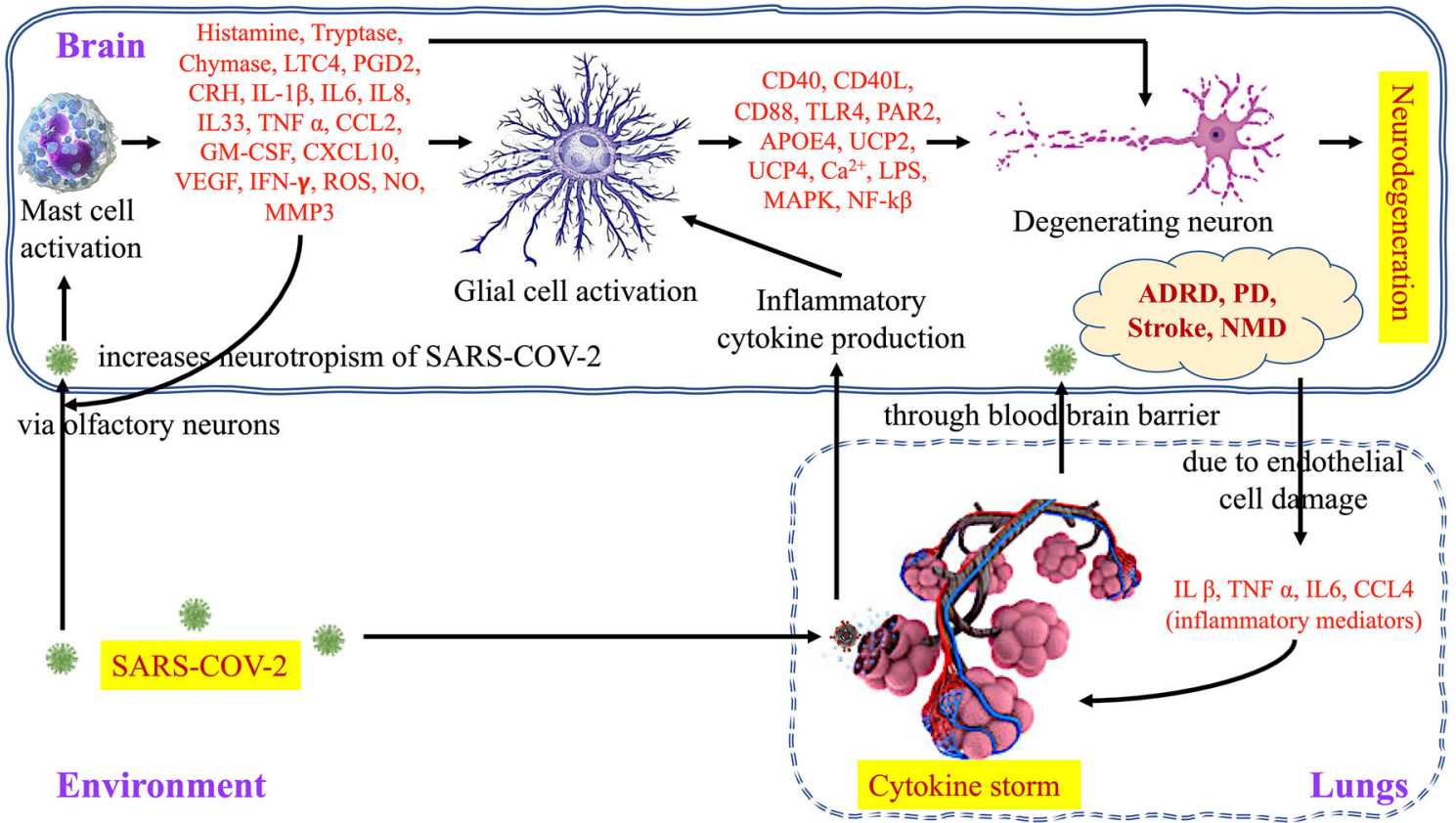

Fig. 2 Immunological crosstalk between infected lungs and the brain, and possible neurodegenerative amelioration. Immune reactions are started against the SARS-COV-2 infection both in the lungs and the brain, activated mast cells release pre-formed and newly formed inflammatory mediators in the brain subsequently activating the glial cells which can lead to neuron degeneration while cytokine storm is taking place in lungs,

and loneliness in patients and could induce various symptoms such as tremor, gait, and dyskinesia [87, 88].

\section{Stroke}

On the one hand, the COVID-19 pandemic has increased the risk of complications and mortality in patients who have experienced stroke [89]; on the other hand, stroke is a common comorbidity among patients with COVID-19. The patients have to be protected further from infected individuals, which increase the responsibilities of healthcare professionals. Healthcare facilities previously dedicated to stroke-related cases, such as ICU, wards, and health workers, have been allocated to COVID-19-related cases owing to the emergency situation in the pandemic, as stated by the World Stroke Organization. There has been a significant reduction in the hospital admission of patients with acute stroke worldwide, with approximately 50 to $80 \%$ reduction in few countries [90]. This suggests that individuals who have suffered a mild stroke, who could avail hospital facilities under normal conditions, are currently not allowed admission owing to the apprehension of patients contracting COVID-19.

Several mechanisms that might increase stroke risk due to COVID-19 have been identified; however, these are yet to be confirmed. Few mechanisms such as CS, increased D-dimer levels, and direct brain injury by the virus have been reported $[19,91]$. In a study in Wuhan, China, the effect of a history of and cytokine from lungs can reach the brain through blood-brain barrier and may further aggravate the neurological complications. Under this circumstance, the patients suffering from neurological disorders (ADRD, PD, stroke, NMD) have a high risk of developing comorbidities and may require special attention from the medical support system

the stroke and other neurological problems on COVID-19 symptoms was compared between patients. The study concluded that patients with COVID-19 who had previously experienced neurological symptoms exhibited more severe clinical symptoms than those without a history of disease. The symptoms included dizziness, impaired consciousness, ataxia, and seizures [92]. SARS-CoV-2 infection was confirmed in an 84-year-old female patient suffering from embolic stroke and non-anticoagulated atrial fibrillation, following which the patient died. It was concluded that elderly patients with COVID-19 and a stroke history are at a higher risk of death [93]. Zhai et al. described the case of a patient admitted to Hubei Provincial Hospital of Chinese Traditional Medicine (Guanggu, Wuhan, Hubei Province, China) presenting with weakness in the right limb and slight cough for 1 week. He was later diagnosed with COVID-19 with hypoxemia and excessive cytokine secretion, which led to the development of ischemic stroke [94]. Avula et al. discussed four confirmed cases of ischemic stroke and PCR-confirmed SARS-CoV-2 infection in another case study [95].

Abdulkadir et al. studied four patients with COVID-19 who also exhibited symptoms of cerebral stroke. The patients presented with stroke and infection concomitantly. The authors reported that COVID-19 in the elderly is characterized by signs such as neuro-invasion along with respiratory system involvement [96]. Age will always remain a risk factor for both stroke and COVID-19; however, there are studies that 
reported the coincidence of COVID-19 and stroke in young individuals in the USA [97]. In one study, it is reported that the patients having a history of stroke are three times more prone to the risk of death [98].

The exact pathophysiology of the neurotoxic effect of this virus is yet to be determined. SARS-CoV- 2 is considered to be able to induce stroke by several mechanisms (Fig. 3). It could invade the vessel walls, cause coagulation disorders, or destabilize an existing athero-arterial plague or cerebral embolism $[98,99]$. As previously discussed, SARS-CoV-2 enters host cells through the ACE2 receptor, which is also an important component of the rennin-angiotensin system (RAS); hence, it can invade vessel walls, as endothelial cells express the ACE2 receptor. Previous studies have confirmed the presence of SARS-CoV-2 in the endothelium [8]. After the invasion, it can behave in the same manner as the Varicella-zoster virus, which triggers stroke in patients. This causes inflammation and necrosis of cerebral arterial walls [100]. Viruses can also cause thrombosis, which affects coagulation, platelet activation, and endothelial infiltration upon the activation of the immune system [101]. CS, which is an inflammatory process commonly observed in COVID-19, may lead to increased Ddimer levels and coagulation [102, 103]. In the case of stroke patients, as SARS-CoV-2 binds to ACE2, ACE2's activity in providing neuroprotection will be hindered. The inflammatory reaction is also triggered in the ischemic penumbra owing to the dysregulation of ACE2 [104]. The main function of RAS is to maintain homeostasis in the brain, along with several involuntary functions. In the case of stroke, the brain RAS plays a pivotal role. It is activated in stroke leading to inflammatory responses which ultimately activates the downstream immunological pathways [105]. With the multiplication of viral particles, the activation of immune response results in $\mathrm{CS}$, which can persuade to acute respiratory distress syndrome (ARDS) [106]. Studies reported that ARDS causes cough and breathing problems in COVID patients. The risk of COVID19 infection in stroke patients, as well as the risk of stroke in COVID-19 patients, may be very high since the evidence reflects the strong brain-lung interaction and immunological crosstalk between the two systems $[50,51]$.

With respect to the above discussion on the impact of stroke on patients with COVID-19, several recommendations should be adopted to decrease the malaise of the present situation. To provide stroke-care facilities, all facets of stroke treatment have to be reorganized for providing rapid care without infecting patients. Several awareness programs have to be conducted by means of teleservices, virtual check-ups, and acute treatment to reduce the morbidity and mortality

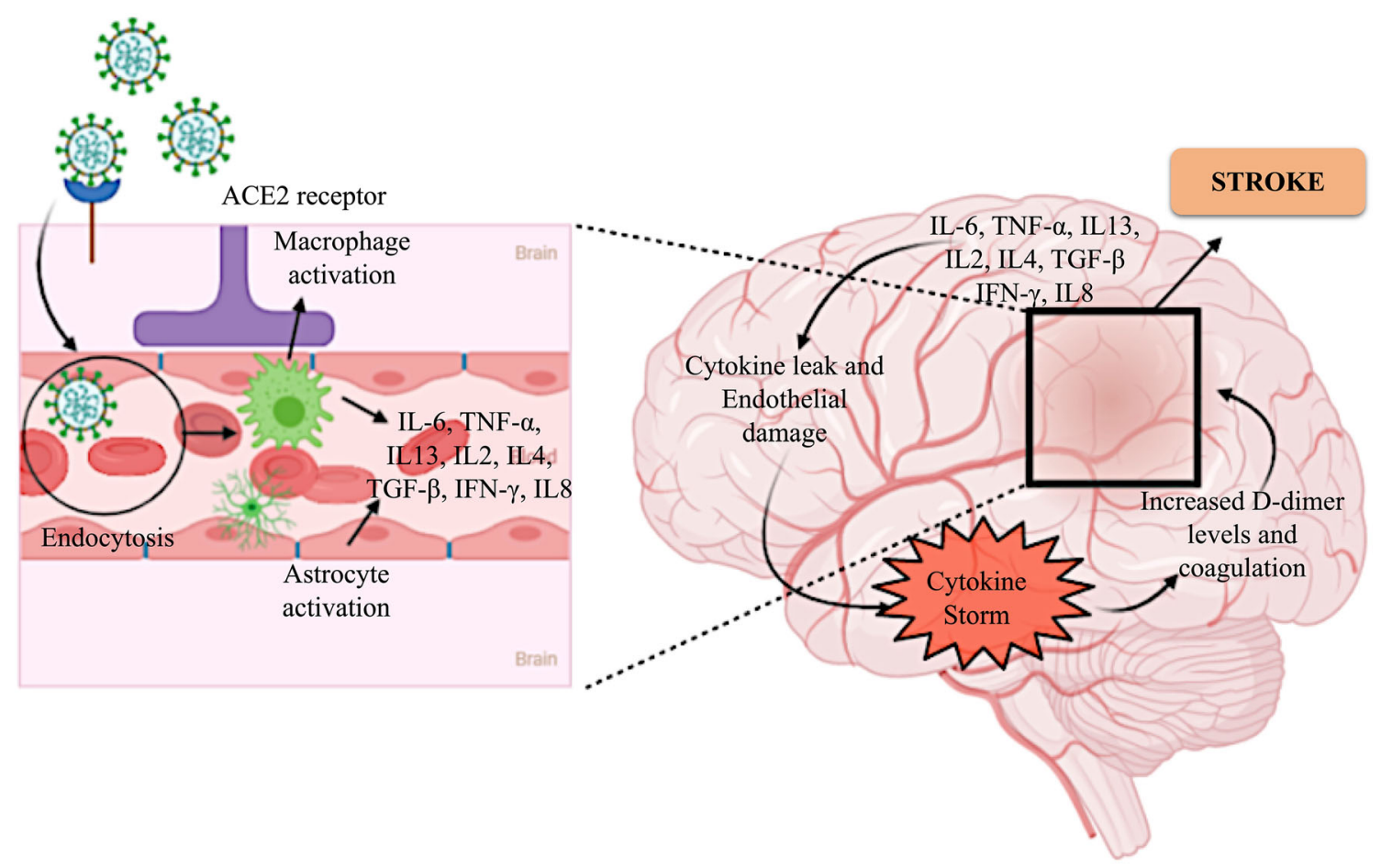

Fig. 3 Mechanism of induction of cytokine storm and subsequent stroke by severe acute respiratory syndrome coronavirus 2 (SARS-CoV-2). SARS-CoV-2 binds to the ACE2 receptor expressed on endothelial cells and enters the blood stream by endocytosis. The entrance of the viral particle, detected as a foreign body, leads to the activation of macrophages and astrocytes. This consequently triggers the release of cytokines from these cells and also from other cells of the endothelium. The cytokines eventually cause endothelial damage and capillary leak, which leads to a cytokine storm in the brain. This induces an increase in the D-dimer levels and coagulation, which ultimately lead to hypoxia and stroke 
among stroke patients during the ongoing pandemic [107]. Resource management practices should be established as rapidly as possible.

\section{Neuromuscular Diseases (NMDs)}

We have discussed above that the risk for COVID-19 is higher in patients with existing conditions, as the immune system is compromised in such individuals, and the virus can invade host cells easily. There are several studies and case report available on $\mathrm{AD}, \mathrm{PD}$, and stroke; however, there are limited data available on NMDs. A study conducted in China reported that COVID-19 could have affect myopathies, as approximately $60 \%$ hospitalized patients presented with fatigue or myalgia [102, 108], which would subsequently cause viral myositis. Critically ill patients may develop polyneuropathy [109]. The findings from these case studies show that COVID19 can induce NMDs as well.

Guidon and Amato hypothesized that there is an increase in disease worsening and incidences in patients diagnosed with NMD who were subsequently infected by SARS-CoV-2 under the ongoing pandemic [110]. The risks for several autoimmune diseases, such as myositis; myasthenia gravis; multifocal acquired demyelinating sensory and motor neuropathy; and degenerative disorders such as amyotrophic lateral sclerosis (ALS), hereditary neuropathies, and motor neuron disease are exacerbated by COVID-19 [111]. Patients with NMDs are administered immunosuppressant drugs on a regular basis, which poses a major risk for infections of any type, particularly COVID-19. In such patients, the disease can have more severe manifestations post-contraction of COVID-19. Even vaccines are less effective in immunosuppressed individuals. The drugs used for the treatment of COVID-19, such as chloroquine and hydroxychloroquine, can trigger toxicities such as neuropathy in such patients.

To date, there are no definite recommendations for treatment management of patients with NMDs and COVID-19, and considerable research is required in this field. Close monitoring is essential for patients who are suffering from NMDs and COVID-19 concomitantly to track those exhibiting a rapid decline in respiratory function. For this, remote monitoring is necessary. Patients with NMD who are administered corticosteroids may require stress doses [112]. The system for the treatment and management of patients with NMD requires significant improvisations. Every country has released guidelines with respect to the clinic and hospital visits and telemedicine for patients with NMD during the ongoing pandemic. COVID-19 has also affected training and research in the field of NMD treatment, as the current sessions could not be conducted under lockdown, and the next session may also be limited [110].

The probability that SARS-CoV-2 can remain latent in the CNS cannot be ruled out. If so, delayed neurological complications may be established due to medium- or longterm virus reactivation, causing a sequence of neuroinflammatory pathways involved with a neurodegenerative disorder.

\section{THERAPEUTIC APPROACHES FOR COVID-19}

The identification and investigation of neurological signs and symptoms in COVID-19 patients are significant for designing treatment protocol against the neurological effects [19]. The First Few X (FFX) cases and contact investigation protocol designed by WHO for COVID-19 also enquire about "other neurological signs" under the section of "other symptoms and pre-existing chronic neurological impairments" $[112,113]$. The COVID-19 pandemic has led to the discovery and development of new vaccines, treatment, and therapeutic strategies against the CoVs. The multiple pathways, discussed above, such as systemic circulation through BBB or across the cribriform plate at the olfactory bulb, are believed to be involved in the movement of the COVID-19 virus to the brain, and resultantly, can be targeted for developing various therapeutic strategies [101, 114]. Additionally, patients with COVID-19 were reported to suffer from convulsions. However, distinguishing neurological convulsions from febrile convulsions in patients with high-grade fever may aid the development of alternative COVID-19 treatment approaches [115].

Currently, numerous vaccines/therapeutics have been in different stages of clinical development. A small number of such vaccines/therapeutics have exhibited the potential and yielded favorable results in the control of COVID-19 and the associated viral load. The major goals of these vaccines/ therapeutic interventions are to decrease viral load, limit disease severity, reverse hypoxemia, and provide adequate organ support [116]. In this section, the methodologies and advancements for alleviating neurological problems have been discussed along with the development of up-and-coming vaccines/therapeutics for COVID-19, the challenges involved, and the potential alternative strategies.

\section{Chloroquine and Other Drugs}

Chloroquine and its synthetic derivative hydroxychloroquine are well-established medication for malaria and autoimmune disorders such as rheumatoid arthritis, lupus, and porphyria cutanea tarda [117]. In recent times, these drugs have demonstrated antiviral activities against HIV, Zika virus, and CoV. Chloroquine, hydroxychloroquine, and other 4aminoquinoline compounds were observed to prevent viral infection in vitro by raising endosomal $\mathrm{pH}$ after crossing the vacuolar membrane [118]. Lower $\mathrm{pH}$ is a pre-requisite for the fusion of the cell membrane of the virus. Chloroquine inhibits terminal glycosylation of the ACE2 receptors present on the 
host cell surface [119]. This alteration in the host cell ACE2 receptor leads to a change in the interaction between the spike protein and the ACE2 receptor, which is another prerequisite for virus-cell membrane fusion. The diagrammatic representation is depicted in Fig. 4a. Chloroquine interference in viral replication and host-cell entry has been reported in infections by numerous viruses, such as Borna disease virus (BDV), mice minute virus, avian leukosis virus, and hepatitis A virus, apart from HIV and Zika virus [120, 121].

Furthermore, chloroquine is used as a non-steroidal drug to combat inflammatory response in various disorders like lupus erythematosus, rheumatoid arthritis, and multiple sclerosis. The anti-inflammatory activity of chloroquine is primarily attributed to the dose-dependent elevation of the cyclin-

(a)

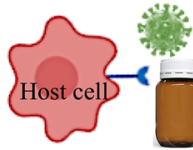

Hydroxychloroquine inhibits the terminal glycosylation of ACE2 receptors (b)

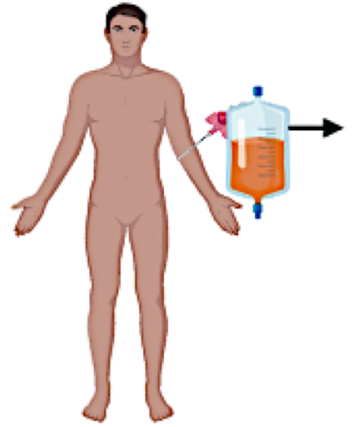

Donor recovered from COVID 19

(c)

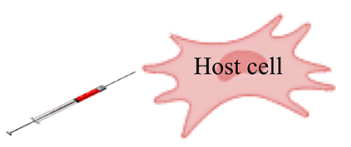

Intravenously administration of stem cells into the infected host

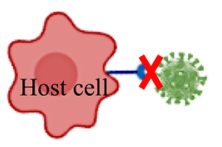

It leads to the inhibition of binding of virus to the host cells

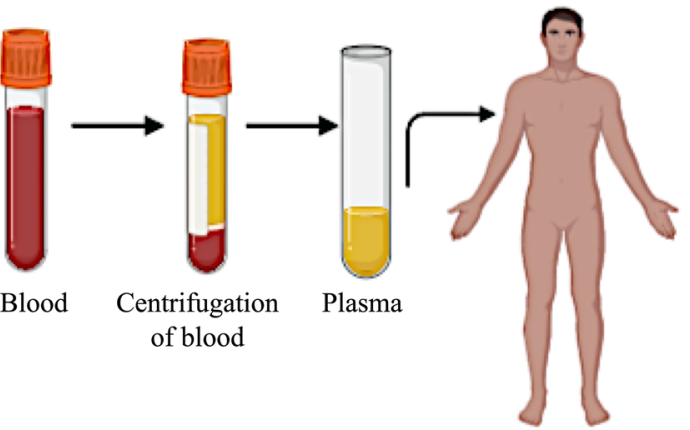

Plasma recipient affected from COVID 19

(d)

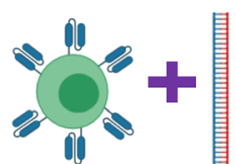

\section{Genetic} Engineering

Isolated T-Cell DNA

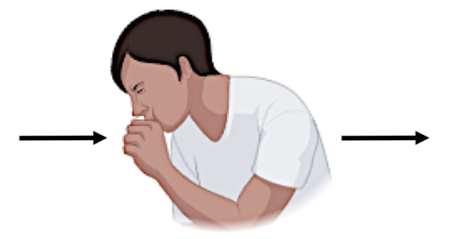

Stem cells escape due to lack of ACE2 receptors which leads to the healing of the patient

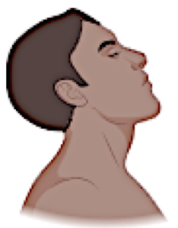

Recovery of the patient is observed

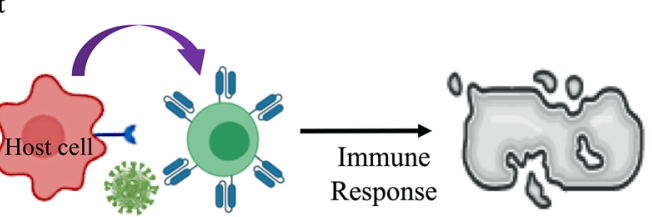

Damaged virus can not spread further infection

(e)

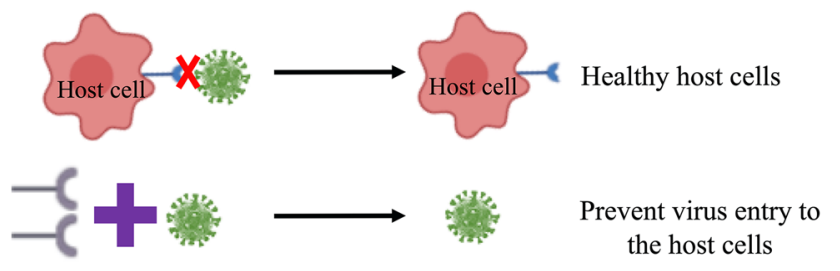

Soluble recombinant ACE2 receptors with high affinity to virus

Fig. 4 Diagrammatic representation of therapeutic strategies,(a) Chloroquine and other drugs.(b) Plasma-based therapy.(c) Cell-based therapy.(d) Chimeric antigen T-cell therapy.(e) Soluble recombinant ACE2 receptor therapy 
dependent kinase inhibitor $\mathrm{p} 21$, inhibition of $\mathrm{T}$ cell proliferation, and development of IFN- $\gamma$-producing Th1 cells [122]. Chloroquine might weaken COVID-19 pathology, as it reportedly elicits an inflammatory response as the disease progresses [123]. However, in addition to the positive effects of chloroquine, there are reports of undesirable effects such as QT prolongation, ventricular arrhythmia, hypotension, and other symptoms of cardiac toxicity, including alterations in the repolarization and depolarization cycle of cardiac and skeletal muscles [124]. This indicates the importance of establishing and following proper protocol while using chloroquine for treating patients with COVID-19. Even though chloroquine showed promising results in COVID-19 treatment, the absence of substantial data and the likely safety concern cannot be overlooked and should be investigated.

The acute respiratory distress and high morbidity observed after $\mathrm{CoV}$ infection are associated with CS responsible for elevated pro-inflammatory cytokine levels in plasma [125]. Tocilizumab, an immunosuppressive monoclonal antibody drug, has demonstrated encouraging clinical outcomes along with a favorable safety profile [126]. It is a humanized monoclonal antibody primarily used for treating rheumatoid arthritis and systemic juvenile idiopathic arthritis. It improves respiratory function, suppresses CS, and normalizes body temperature by targeting the interleukin- 6 receptor. Similarly, tacrolimus and prednisolone administered at low doses inhibit the expression of pro-inflammatory cytokines that worsen lung condition. Similarly, drugs used for treating hypertension, including lisinopril (ACE inhibitor) and losartan (angiotensin II receptor-blocker), were observed to upregulate the expression of ACE2 receptors, and consequently aggravate viral infection [127]. Presently, the efficacy and evaluation of these two immunosuppressants, particularly with respect to their effects in reducing secondary pathological symptoms in patients with COVID-19, are under investigation through clinical trials.

\section{Plasma Exchange Therapy}

Plasma exchange therapy, also known as convalescent plasma therapy (CPT), is adaptive immunotherapy commonly employed in the prevention and treatment of numerous infectious diseases [128]. For more than a century, this strategy has been employed as a therapy for treatment and eradication of diseases such as rabies, typhoid, cholera, and hepatitis, among others [129]. In recent decades, it has been effectively used to treat SARS, MERS, and the $2009 \mathrm{H} 1 \mathrm{~N} 1$ pandemic, and has shown effectiveness against certain cancers such as melanoma, acute myeloid leukemia, and acute lymphoblastic leukemia among others. Plasma administration is a type of passive immunotherapy and has reportedly improved the patient survival rate in the abovementioned diseases.
Similar results of shortened hospital stay and reduced mortality rates have also been observed in patients with SARS who underwent CPT. SARS, MERS, and COVID-19 are akin in terms of virological and clinical characteristics, analogous results of lower mortality rates were observed in various studies on COVID-19 patients as well. Therefore, plasma exchange therapy might be an effective method for COVID-19 pandemic control. However, only patients who have recovered from COVID-19 and have a high neutralizing antibody concentration can act as plasma donors (Fig. 4b) [130]. Regardless, the best treatment outcome of plasma exchange therapy in SARS patients has been observed with early administration, i.e., within a fortnight after infection.

However, the full scale of benefit/risk ratio of plasma exchange therapy for patients of COVID-19 remains unexplored. One of the major drawbacks of the plasma therapy is the possibility of infection advancement as well as transfusion-related acute lung injury owing to an inadequate titer of neutralizing antibodies in plasma. Apart from determining the optimal concentration of neutralizing antibodies, the dynamic variations in cytokine levels as well as a reduction in SARS-CoV-2 RNA/genomic material with respect to CPT administration (plasma shot) must be confirmed for the development of an effective therapeutic protocol.

\section{Cell-based Therapy}

Cell-based therapies primarily aim to replace or repair the damaged tissues through transplantation or trophic effect [131]. The mechanisms underlying disease initiation and progression are generally targeted during cell therapy by utilizing stem, progenitor, or primary cell types. Cell therapy-based clinical trials using stem cells for the treatment of SARSCoV-2 infection are currently underway in several countries, including the USA, China, Russia, Brazil, and Jordan. Mesenchymal stromal cells (MSCs) have been employed in the majority of these clinical trials owing to the absence of ethical concerns associated with the less invasive acquisition procedure and the high proliferation rate of the cells [132].

Additionally, isolation of MSCs can be done easily from various tissues, such as adipose tissue, bone marrow, cord blood, peripheral blood, menstrual blood, dental pulp, buccal fat pad, Wharton jelly, and fetal liver [133, 134]. Furthermore, the long-term storage potential, easy and rapid expansion to clinical volumes and the safety and efficacy of use adds to the advantages of MSCs over other cell-based technologies and makes them a popular treatment choice. While multiple clinical trials on the treatment of various diseases using MSCs are currently underway, still none has been recommended for the treatment of COVID-19 to date. The effect of human MSC administration in case influenza virus $\mathrm{A} / \mathrm{H} 5 \mathrm{~N} 1$ infection was investigated in 2016; the findings showed that the treatment 
was able to reduce the influenza virus $\mathrm{A} / \mathrm{H} 5 \mathrm{~N} 1$-induced acute lung injury and increased survival in mice [135].

Notably, subsequent to COVID-19 infection, the production and the release of inflammatory factors by the host immune system are significantly enhanced; this leads to CS and an increased number of immune cells [136]. The release of these pro-inflammatory cytokines might be inhibited by MSC therapy [137]. The regenerative properties of stem cells and the secretion of growth factors such as VEGF, PDGF, FGF, and TGF- $\beta$ also enhanced the repair of injured tissues [138]. Both regenerative properties and growth factors of stem cells curb the inflammation in addition to regulating endothelial and epithelial permeability; this subsequently enhances the regeneration/repair of endogenous tissue. Moreover, MSCs secrete various antimicrobial peptides and proteins (LL-37, defensins, hepcidin, and lipocalins) by MSCs could lead to the reduction of viral load in patients with COVID-19 [139].

Accordingly, it was predicted that the intravenous infusion of MSCs and their subsequent movement into the lungs would protect alveolar epithelial cells, restore the pulmonary microenvironment, sequentially salvage lung function, and prevent pulmonary fibrosis in patients with COVID-19 [140]. MSCs do not express ACE2 receptors and TMPRSS2, which prevents recognition by viral particles and facilitates healing via regeneration of cells [141]. The basis of cell-based therapy is presented in Fig. 4c. Recently, seven critical COVID-19 patients were administered clinical-grade human MSCs and monitored for multiple responses. Albeit the patients survived and recovered after intravenous administration of MSCs; however, the adverse effects of MSC administration were observed and reported. Owing to the absence of a large-scale study on MSC administration and observation, there are no conclusive evidence reported. Therefore, a large-scale study is urgently needed for the development of an effective therapeutic strategy.

\section{Chimeric Antigen Receptor T-Cell (CAR-T) Therapy}

CAR-T cells are genetically engineered T-cells containing a single receptor for both antigen-binding and T-cell-activating functions [142]. The basis of CAR-T therapy is the transformation of T-cells to facilitate the effective recognition of specific antigens effectively and their subsequent elimination. Initially, T-cells were isolated, and DNA was incorporated through genetic engineering methods to enable the expression of chimeric antigen receptors (CARs) on the surface of the cells; these re-engineered T-cells are known as CAR-T cells [143]. The graphic representation of the process is depicted in Fig. 4d. The potential of CAR-T cells for identifying antigens and eliminating virus-infected or cancer cells constitutes an incredibly promising approach and has been demonstrated in experiments showing the successful treatment of B cell malignancies $[144,145]$. Similar encouraging results have been observed after the treatment of chronic hepatitis B virus (HBV) infection, HIV infection, and HBV-related hepatocellular carcinoma using CAR-T therapy [146]. As pathogenspecific T-cells have a significant contribution in controlling the progression of such viral diseases, CAR-T therapy might also have a pivotal role in regulating other infectious diseases.

The process of CAR-T cell formation, i.e., T-cell extraction from the blood of either a patient or from a healthy donor, and their subsequent reprogramming for targeting virus-infected cells or the virus itself could be expensive and unwarranted for the treatment of most viral infections [147]. However, due to the dearth of other definitive COVID-19 treatment options, this could serve as a viable treatment strategy. Conversely, the use of CAR-T cells that stably express pathogen-specific Tcell receptors in COVID-19 treatment could lead to excessive swelling and tissue damage owing to the proliferation of these cells and the elimination of infected cells. Additionally, lung inflammation caused by CS has been reported in patients with extreme symptoms of COVID-19. Re-engineering of T-cells with transient mRNA transfection instead of DNA transformation may be an effective strategy for preventing tissue inflammation and damage. Transient mRNA transfection would only result in temporary CAR expression (spanning 3-5 days) and likely reduce the risk of cytokine-mediated cytotoxicity coupled with off-target tissue damage [148]. Based on this, the dosage and injection schedule of CAR-T-cells for COVID-19 treatment should be designed carefully.

\section{Other Approaches}

Apart from the approaches mentioned above, other pharmaceutical interventions for early detection of COVID-19 or effective restriction of transmission and infection are also being investigated actively. In one approach, soluble recombinant human ACE2 has been administered owing to its higher binding affinity with the virus compared to that of ACE2 receptors present on host cells [149]. This approach was aimed at preventing viral entry into the host cells. The graphic representation of soluble ACE2 receptor application is shown in Fig. 4e. Promising preclinical outcomes from this approach have expedited its progression into clinical trials. Another approach targets the inhibition of a protein involved in viral spike protein expression. The host serine protease TMPRSS2 is known to be crucial for spike protein expression in highly pathogenic human coronaviruses [10]. Camostatmesilate is a candidate drug that inhibits TMPRSS2 and is primarily prescribed to control postoperative reflux esophagitis and chronic pancreatitis [150]. In the pathogenic mouse model, it reportedly limited the spread of SARS-CoV-2 and the consequent pathogenesis. Previously observed high efficacy of Camostatmesilate against SARSCoV might also be achieved in COVID-19 treatment; for this purpose, it is currently under clinical trial [151]. Herbal and 
medicinal plants and phytochemicals like Caesalpinia sappan, Terminalia chebula, Calanolide A, and SP-303 which is isolated from the latex of a Latin American plant Croton lechleri are in process to see the effects on COVID-19induced infections [152].

\section{THE DEVELOPMENT OF VACCINE AGAINST COVID-19}

The development of a vaccine is the safest and most reliable approach for escaping from the pandemic [153]. The scientific community from all over the world is constantly working in the field of vaccine production against COVID 19. The vaccine industry has responded on urgent basis toward the pandemic of COVID-19 for supporting the developmental vaccine program against SARS-CoV-2 [154]. There is a current situation and urgent need to open up numerous platforms for vaccine development. Some vaccines are still under human clinical trials [155] and others have been approved which are available in the market. The information regarding the approved vaccines is listed in Table 1 . Some vaccines have been recently entered the clinical trial phases like Convidicea (Ad5nCoV), AZD1222, Covaxin, JNJ-78436735 (formerly Ad26.COV2.S), and NVX-CoV2373 (in phase 3 trial).

The vaccines are categorized under different genomic parts like genetically engineered mRNA or DNA containing instructions for making copies of the $\mathrm{S}$ protein, bacterial/adenoviral/lentiviral vector-based vaccines, and inactivated SARS-CoV-2 itself [156]. DNA- and mRNA-based platforms provide the pliability toward the manufacture process and antigen manipulation. To target the frequent mutations in the antigen epitope, mRNA and DNA vaccines facilitate to change in the antigen coding gene series in the antigenic epitopes [157]. At present, scientists are working for the licensed DNA/mRNA vaccines for use in humans. Some vaccines are already developed and show the effectiveness of numerous infectious diseases. The mRNA vaccines have also been found to restore the immune (innate and adaptive both) response against COVID-19.

From the above treatment strategy, the indirect therapeutic effects would be estimated in SARS-Co-V-2 associated health issues like heart, kidney, and neuronal complications. Therefore, it is believed that neurological complications would also be sorted out with the above discussed targeted therapies.

\section{SUMMARY AND CONCLUSION}

Beyond pulmonary disorders, various neurological complications have been described in COVID-19 patients, including headache, myalgia, dizziness, and anosmia, along with encephalitis, encephalopathy, necrotizing hemorrhagic

Table 1 List of approved vaccines. The information was retrieved from https://www.raps.org/news-and-articles/news-articles/2020/3/covid-19vaccine-tracker and https://vaccine.icmr.org.in/covid-19-vaccine

\begin{tabular}{|c|c|c|c|c|c|}
\hline $\begin{array}{l}\text { Serial } \\
\text { number }\end{array}$ & Name & Vaccine type & Primary developers & $\begin{array}{l}\text { Country of } \\
\text { origin }\end{array}$ & Authorization/approval \\
\hline 1. & BNT162b2 & mRNA-based vaccine & Pfizer, BioNTech; Fosun Pharma & Multinational & $\begin{array}{l}\text { UK, Bahrain, Canada, Mexico, } \\
\text { USA, Singapore, Oman, Saudi } \\
\text { Arabia, Kuwait, EU }\end{array}$ \\
\hline 2. & mRNA-1273 & mRNA-based vaccine & Moderna, BARDA, NIAID & USA & USA, Canada \\
\hline 3. & CoronaVac & $\begin{array}{l}\text { Inactivated vaccine } \\
\text { (formalin with alum } \\
\text { adjuvant) }\end{array}$ & Sinovac & China & China \\
\hline 4. & $\begin{array}{l}\text { No name } \\
\text { announced }\end{array}$ & Inactivated vaccine & $\begin{array}{l}\text { Wuhan Institute of Biological Products; China } \\
\text { National Pharmaceutical Group (Sinopharm) }\end{array}$ & China & China \\
\hline 5. & Sputnik V & $\begin{array}{l}\text { Non-replicating viral } \\
\text { vector }\end{array}$ & $\begin{array}{l}\text { Gamaleya Research Institute, Acellena Contract } \\
\text { Drug Research and Development }\end{array}$ & Russia & Russia \\
\hline 6. & BBIBP-CorV & Inactivated vaccine & $\begin{array}{l}\text { Beijing Institute of Biological Products; China } \\
\text { National Pharmaceutical Group (Sinopharm) }\end{array}$ & China & $\begin{array}{l}\text { China, United Arab Emirates, } \\
\text { Bahrain }\end{array}$ \\
\hline 7. & EpiVacCorona & Peptide vaccine & $\begin{array}{l}\text { Federal Budgetary Research Institution State } \\
\text { Research Center of Virology and } \\
\text { Biotechnology }\end{array}$ & Russia & Russia \\
\hline 8. & COVAXIN & Inactivated Vaccine & $\begin{array}{l}\text { Bharat Biotech in collaboration with the Indian } \\
\text { Council of Medical Research (ICMR) - } \\
\text { National Institute of Virology (NIV) }\end{array}$ & India & India \\
\hline 9. & Covishield & $\begin{array}{l}\text { Weakened version of } \\
\text { a common cold } \\
\text { virus (adenovirus) }\end{array}$ & $\begin{array}{l}\text { Serum Institute of India (SII) and Indian Council } \\
\text { of Medical Research (ICMR) }\end{array}$ & India & India \\
\hline
\end{tabular}


encephalopathy, stroke, epileptic seizures, rhabdomyolysis, and Guillain-Barre syndrome. It is already reported that SARS causing viruses, SARS-CoV and SARS-CoV-2, have common genetic sequences with ACE2 receptors rapport to enter the host cells [158]. The possibility of CNS infection in patients with COVID-19 must be considered by the neurologists throughout the world. Injury to the nervous system could also result from cascade events induced by the loss of oxygen owing to lung damage, which may lead to various organ impairments. The complete process of developing a critical illness may also have a significant role for the enhancement of neurological abnormalities. The primary infection could occur in the brain stem - principally in the part that has respiratory centers and controls breathing. An infection and any possible impairment in this part of the nervous system could further magnify respiratory problems in the patients. Therefore, it remains unclear if this condition is caused directly by viral entry or if it is a secondary response to the systemic inflammation in patients owing to the deregulated immune response to viral infection.

As clinical practitioners throughout the globe prepare themselves for treating the patients with COVID-19 in the predictable future, the advancement of a comprehensive understanding of the systemic and organ-specific pathophysiology and clinical complications of this system-wide disease is required. Now, it has become more imperative to identify and explain the significances of research on $\mathrm{CoV}$ that will help to pursue multiple aspects of this poorly elucidated disease. Concisely, the areas that seek immediate attention include interpretation of the mechanism attributed to the extrapulmonary distribution of SARS-CoV-2, understanding the virus characteristics that may augment its spread in neuronal tissues, the contribution of neuropathophysiology, the consequences of anti-inflammatory therapies on CNS, prediction of the long-term effects on cognition and neuropsychiatry, documentation of reasons that describe the variability in the management and gravity of the related neuronal ailments, and the biological and social machinery underlying the disparities in final outcomes of neuro-comorbid situations. There is also a need for universal definitions and data standards for the research on COVID-19-related complications. Collaboration among the scientists and clinicians working at regional, national, and international levels who focus on transparent, ethical, and high-quality research will definitely help the humanity to get success against the ongoing pandemic.

Acknowledgements The author would like to thank Deanship of Scientific Research at Majmaah University for supporting this work.

Author Contribution All authors contributed to the study conception and design. Manuscript outline preparation was done by Sadaf Jahan; manuscript writing is done by Dipak Kumar, Sadaf Jahan, Andleeb Khan, and Arif Jamal Siddiqui; revision of the manuscript was done by Neeru Singh
Redhu, Wahajuddin, and Johra khan; vaccine table is prepared by Bader Alshehri; proofreading is done by Saeed Banwas and Mohammed Alaidarous and all authors commented on previous versions of the manuscript. All authors have read and approved the final manuscript.

Funding The Author would like to thanks to the Deanship of Scientific Research at Majmaah University for supporting the work under Project Number R-2021-24.

\section{Declarations}

Consent to Participate Not applicable

Consent for Publication Not applicable

Conflict of Interest The authors of the manuscript declare no conflict of interest/competing interests.

All data and materials are available in the manuscript.

\section{References}

1. Nicholls JM, Poon LL, Lee KC, Ng WF, Lai ST, Leung CY, Chu CM, Hui PK et al (2003) Lung pathology of fatal severe acute respiratory syndrome. Lancet 361(9371): 1773-1778

2. Peiris J, Lai S, Poon L, Guan Y, Yam L, Lim W, Nicholls J, Yee $\mathrm{W}$ et al (2003) Coronavirus as a possible cause of severe acute respiratory syndrome. Lancet 361(9366):1319-1325

3. Gupta A, Madhavan MV, Sehgal K, Nair N, Mahajan S, Sehrawat TS, Bikdeli B, Ahluwalia N et al (2020) Extrapulmonary manifestations of COVID-19. Nat Med 26(7):1017-1032

4. Zheng KI, Feng G, Liu WY, Targher G, Byrne CD, Zheng MH (2020) Extra-pulmonary complications of COVID-19: a multisystem disease? J Med Virol

5. Bartlam M, Yang H, Rao Z (2005) Structural insights into SARS coronavirus proteins. Curr Opin Struct Biol 15(6):664-672

6. Arabi Y, Harthi A, Hussein J, Bouchama A, Johani S, Hajeer A, Saeed B, Wahbi A et al (2015) Severe neurologic syndrome associated with Middle East respiratory syndrome corona virus (MERS-CoV). Infection 43(4):495-501

7. Yin Y, Wunderink RG (2018) MERS, SARS and other coronaviruses as causes of pneumonia. Respirology 23(2):130 137

8. Paniz-Mondolfi A, Bryce C, Grimes Z, Gordon RE, Reidy J, Lednicky J, Sordillo EM, Fowkes M (2020) Central nervous system involvement by severe acute respiratory syndrome coronavirus-2 (SARS-CoV-2). J Med Virol 92(7):699-702

9. Guedj E, Million M, Dudouet P, Tissot-Dupont H, Bregeon F, Cammilleri S, Raoult D (2020) 18 F-FDG brain PET hypometabolism in post-SARS-CoV-2 infection: substrate for persistent/delayed disorders? Eur J Nucl Med Mol Imaging:1-4

10. Hoffmann M, Kleine-Weber H, Schroeder S, Krüger N, Herrler T, Erichsen S, Schiergens TS, Herrler G et al (2020) SARS-CoV-2 cell entry depends on ACE2 and TMPRSS2 and is blocked by a clinically proven protease inhibitor. Cell.

11. Hamming I, Timens W, Bulthuis M, Lely AT, Navis GJ, van Goor $\mathrm{H}$ (2004) Tissue distribution of ACE2 protein, the functional receptor for SARS coronavirus. A first step in understanding SARS pathogenesis. J Pathol 203(2):631-637

12. Kermani N, Song W-J, Lunt A, Badi Y, Versi A, Yike G, Sun K, Bhavsar P, Howarth P, Dahlen S-E (2020) Airway expression of SARS-CoV-2 receptor, ACE2, and proteases, TMPRSS2 and furin, in severe asthma. medRxiv. 
13. Li K, Wohlford-Lenane C, Perlman S, Zhao J, Jewell AK, Reznikov LR, Gibson-Corley KN, Meyerholz DK et al (2016) Middle East respiratory syndrome coronavirus causes multiple organ damage and lethal disease in mice transgenic for human dipeptidyl peptidase 4. J Infect Dis 213(5):712-722

14. Subhramanyam CS, Wang C, Hu Q, Dheen ST Microgliamediated neuroinflammation in neurodegenerative diseases. In: Seminars in cell \& developmental biology, 2019. Elsevier, pp 112-120.

15. Voet S, Srinivasan S, Lamkanfi M, van Loo G (2019) Inflammasomes in neuroinflammatory and neurodegenerative diseases. EMBO Mol Med 11(6):e10248

16. Aljanabi NM, Mamtani S, Al-Ghuraibawi MMH, Yadav S, Nasr L (2020) Alzheimer's and hyperglycemia: role of the insulin signaling pathway and GSK-3 inhibition in paving a path to dementia. Cureus 12(2)

17. Zubair AS, McAlpine LS, Gardin T, Farhadian S, Kuruvilla DE, Spudich S (2020) Neuropathogenesis and neurologic manifestations of the coronaviruses in the age of coronavirus disease 2019: a review. JAMA Neurol

18. Mirza J, Ganguly A, Ostrovskaya A, Tusher A, Viswanathan R (2020) Command suicidal hallucination as initial presentation of coronavirus disease 2019 (COVID-19): a case report. Psychosomatics.

19. Mao L, Jin H, Wang M, Hu Y, Chen S, He Q, Chang J, Hong C et al (2020) Neurologic manifestations of hospitalized patients with coronavirus disease 2019 in Wuhan, China. JAMA Neurol 77(6):683-690

20. Zhang G, Zhang J, Wang B, Zhu X, Wang Q, Qiu S (2020) Analysis of clinical characteristics and laboratory findings of 95 cases of 2019 novel coronavirus pneumonia in Wuhan, China: a retrospective analysis. Respir Res 21(1):1-10

21. Wu Y, Xu X, Chen Z, Duan J, Hashimoto K, Yang L, Liu C, Yang C (2020) Nervous system involvement after infection with COVID-19 and other coronaviruses. Brain Behav Immun

22. Hu B, Huang S, Yin L (2020) The cytokine storm and COVID-19. J Med Virol

23. Angulo M (2011) SYMPOSIUM 1 functional roles of channels, receptors, and synapses of NG2 cells. GLIA 59:S8-S37

24. Chiu IM, Heesters BA, Ghasemlou N, Von Hehn CA, Zhao F, Tran J, Wainger B, Strominger A et al (2013) Bacteria activate sensory neurons that modulate pain and inflammation. Nature 501(7465):52-57

25. Danielski LG, Della Giustina A, Badawy M, Barichello T, Quevedo J, Dal-Pizzol F, Petronilho F (2018) Brain barrier breakdown as a cause and consequence of neuroinflammation in sepsis. Mol Neurobiol 55(2):1045-1053

26. Davydow DS, Hough CL, Levine DA, Langa KM, Iwashyna TJ (2013) Functional disability, cognitive impairment, and depression after hospitalization for pneumonia. Am J Med 126(7):615624.e615

27. Klimiec E, Dziedzic T, Kowalska K, Slowik A, KlimkowiczMrowiec A (2016) Knowns and unknowns about delirium in stroke: a review. Cogn Behav Neurol 29(4):174-189

28. McEwen BS, Nasca C, Gray JD (2016) Stress effects on neuronal structure: hippocampus, amygdala, and prefrontal cortex. Neuropsychopharmacology 41(1):3-23

29. Murta V, Villarreal A, Ramos AJ (2020) SARS-CoV-2 impact on the central nervous system: are astrocytes and microglia main players or merely bystanders.

30. Hagberg H, Mallard C, Ferriero DM, Vannucci SJ, Levison SW, Vexler ZS, Gressens P (2015) The role of inflammation in perinatal brain injury. Nat Rev Neurol 11(4): 192

31. World Health Organization. (2020). Clinical management of COVID-19: interim guidance, 27 May 2020 (No. WHO/2019nCoV/clinical/2020.5). World Health Organization.
32. Kremer S, Lersy F, de Sèze J, Ferré J-C, Maamar A, Carsin-Nicol $\mathrm{B}$, Collange $\mathrm{O}$, Bonneville $\mathrm{F}$ et al (2020) Brain MRI findings in severe COVID-19: a retrospective observational study. Radiology:202222

33. Bridwell R, Long B, Gottlieb M (2020) Neurologic complications of COVID-19. Am J Emerg Med

34. Moriguchi T, Harii N, Goto J, Harada D, Sugawara H, Takamino J, Ueno M, Sakata H et al (2020) A first case of meningitis/ encephalitis associated with SARS-coronavirus-2. Int J Infect Dis

35. Benveniste H, Liu X, Koundal S, Sanggaard S, Lee H, Wardlaw J (2019) The glymphatic system and waste clearance with brain aging: a review. Gerontology 65(2):106-119

36. Saavedra JM (2020) COVID-19, angiotensin receptor blockers, and the brain. Cell Mol Neurobiol 1

37. Dubé M, Le Coupanec A, Wong AH, Rini JM, Desforges M, Talbot PJ (2018) Axonal transport enables neuron-to-neuron propagation of human coronavirus OC43. J Virol 92(17)

38. Netland J, Meyerholz DK, Moore S, Cassell M, Perlman S (2008) Severe acute respiratory syndrome coronavirus infection causes neuronal death in the absence of encephalitis in mice transgenic for human ACE2. J Virol 82(15):7264-7275

39. Zhai X, Sun J, Yan Z, Zhang J, Zhao J, Zhao Z, Gao Q, He W-T et al (2020) Comparison of severe acute respiratory syndrome coronavirus 2 spike protein binding to ACE2 receptors from human, pets, farm animals, and putative intermediate hosts. J Virol 94(15)

40. Nikoletseas, M. M. (2020). COVID-19 loci of infection: transport pathways and mechanisms. Michael Nikoletseas.

41. Pennisi M, Lanza G, Falzone L, Fisicaro F, Ferri R, Bella R (2020) SARS-CoV-2 and the nervous system: from clinical features to molecular mechanisms. Int J Mol Sci 21(15):5475

42. Miranda-Saksena M, Denes CE, Diefenbach RJ, Cunningham AL (2018) Infection and transport of herpes simplex virus type 1 in neurons: role of the cytoskeleton. Viruses 10(2):92

43. Banerjee S, Bhat MA (2007) Neuron-glial interactions in bloodbrain barrier formation. Annu Rev Neurosci 30:235-258

44. Varghese PM, Tsolaki AG, Yasmin H, Shastri A, Ferluga J, Vatish M, Madan T, Kishore U (2020) Host-pathogen interaction in COVID-19: pathogenesis, potential therapeutics and vaccination strategies. Immunobiology: 152008

45. Dropulić B, Masters CL (1990) Entry of neurotropic arboviruses into the central nervous system: an in vitro study using mouse brain endothelium. J Infect Dis 161(4):685-691

46. Bishokarma S (2020) COVID-19 pandemic: a neurological perspective. J Lumbini Med College 8(1) 3-pages

47. Mok VC, Pendlebury S, Wong A, Alladi S, Au L, Bath PM, Biessels GJ, Chen C et al (2020) Tackling challenges in care of Alzheimer's disease and other dementias amid the COVID-19 pandemic, now and in the future. Alzheimers Dement

48. Grasselli G, Pesenti A, Cecconi M (2020) Critical care utilization for the COVID-19 outbreak in Lombardy, Italy: early experience and forecast during an emergency response. Jama 323(16):15451546

49. Boutoleau-Bretonnière C, Pouclet-Courtemanche H, Gillet A, Bernard A, Laure Deruet A, Gouraud I, Mazoue A, Lamy E et al (2020) The effects of confinement on neuropsychiatric symptoms in Alzheimer's disease during the COVID-19 crisis. J Alzheimer's Dis (Preprint): 1-7

50. Brown EE, Kumar S, Rajji TK, Pollock BG, Mulsant BH (2020) Anticipating and mitigating the impact of COVID-19 pandemic on Alzheimer's disease and related dementias. Am J Geriatr Psychiatry

51. Korczyn AD (2020) Dementia in the COVID-19 period. J Alzheimers Dis 75(4):1071

52. Livingston E, Bucher K (2020) Coronavirus disease 2019 (COVID-19) in Italy. Jama 323(14):1335-1335 
53. Bauer K, Schwarzkopf L, Graessel E, Holle R (2014) A claims data-based comparison of comorbidity in individuals with and without dementia. BMC Geriatr 14(1):10

54. Zhou F, Yu T, Du R, Fan G, Liu Y, Liu Z, Xiang J, Wang Y et al (2020) Clinical course and risk factors for mortality of adult inpatients with COVID-19 in Wuhan, China: a retrospective cohort study. Lancet

55. Guan W-J, Ni Z-y, Hu Y, Liang W-h, Ou C-q, He J-x, Liu L, Shan $\mathrm{H}$ et al (2020) Clinical characteristics of coronavirus disease 2019 in China. N Engl J Med 382(18): 1708-1720

56. Foley NC, Affoo RH, Martin RE (2015) A systematic review and meta-analysis examining pneumonia-associated mortality in dementia. Dement Geriatr Cogn Disord 39(1-2):52-67

57. Ranney ML, Griffeth V, Jha AK (2020) Critical supply shortages - the need for ventilators and personal protective equipment during the Covid-19 pandemic. N Engl J Med 382(18):e41

58. Herrmann LK, Welter E, Leverenz J, Lerner AJ, Udelson N, Kanetsky C, Sajatovic M (2018) A systematic review of dementia-related stigma research: can we move the stigma dial? Am J Geriatr Psychiatry 26(3):316-331

59. Hodson $\mathrm{G}$ (2020) The social lives of dementia caregivers.

60. Farrer LA, Cupples LA, Haines JL, Hyman B, Kukull WA, Mayeux R, Myers RH, Pericak-Vance MA et al (1997) Effects of age, sex, and ethnicity on the association between apolipoprotein E genotype and Alzheimer disease: a meta-analysis. Jama 278(16):1349-1356

61. Kuo C-L, Pilling LC, Atkins JL, Masoli JA, Delgado J, Kuchel GA, Melzer D (2020) APOE e4 genotype predicts severe COVID19 in the UK Biobank community cohort. medRxiv.

62. Bianchetti A, Rozzini R, Guerini F, Boffelli S, Ranieri P, Minelli G, Bianchetti L, Trabucchi M (2020) Clinical presentation of COVID19 in dementia patients. J Nutr Health Aging 1

63. Rea IM, Gibson DS, McGilligan V, McNerlan SE, Alexander HD, Ross OA (2018) Age and age-related diseases: role of inflammation triggers and cytokines. Front Immunol 9:586

64. Scarpa R, Costa L, Del Puente A, Caso F (2020) Role of thymopoiesis and inflamm-aging in COVID-19 phenotype. Pediatr Neonatol 61:364-365

65. Naughton SX, Raval U, Pasinetti GM (2020) Potential novel role of COVID-19 in Alzheimer's disease and preventative mitigation strategies. J Alzheimer's Dis 76(1):21-25

66. Costantini E, D'Angelo C, Reale M (2018) The role of immunosenescence in neurodegenerative diseases. Mediat Inflamm 2018:6039171. https://doi.org/10.1155/2018/6039171

67. Kempuraj D, Selvakumar GP, Ahmed ME, Raikwar SP, Thangavel R, Khan A et al (2020) COVID-19, mast cells, cytokine storm, psychological stress, and neuroinflammation. Neuroscientist: 1073858420941476

68. Bhidayasiri R, Virameteekul S, Kim J-M, Pal PK, Chung S-J (2020) COVID-19: an early review of its global impact and considerations for Parkinson's disease patient care. J Movement Disorder 13(2): 105

69. Yue X, Li H, Yan H, Zhang P, Chang L, Li T (2016) Risk of Parkinson disease in diabetes mellitus: an updated meta-analysis of population-based cohort studies. Medicine 95(18)

70. Hong CT, Hu H-H, Chan L, Bai C-H (2018) Prevalent cerebrovascular and cardiovascular disease in people with Parkinson's disease: a meta-analysis. Clin Epidemiol 10:1147

71. Li YC, Bai WZ, Hashikawa T (2020) The neuroinvasive potential of SARS-CoV2 may play a role in the respiratory failure of COVID-19 patients. J Med Virol 92(6):552-555

72. Lang AE, Espay AJ (2018) Disease modification in Parkinson's disease: current approaches, challenges, and future considerations. Move Disorder 33(5):660-677. https://doi.org/10.1002/mds. 27360
73. Meng L, Shen L, Ji HF (2019) Impact of infection on risk of Parkinson's disease: a quantitative assessment of case-control and cohort studies. J Neurovirol 25(2):221-228

74. Desforges M, Le Coupanec A, Dubeau P, Bourgouin A, Lajoie L, Dubé M, Talbot PJ (2019) Human coronaviruses and other respiratory viruses: underestimated opportunistic pathogens of the central nervous system. Viruses 12(1):14. https://doi.org/10.3390/ v12010014

75. Johnson ME, Stecher B, Labrie V, Brundin L, Brundin P (2019) Triggers, facilitators, and aggravators: redefining Parkinson's disease pathogenesis. Trends Neurosci 42(1):4-13. https://doi.org/ 10.1016/j.tins.2018.09.007

76. Block ML, Zecca L, Hong JS (2007) Microglia-mediated neurotoxicity: uncovering the molecular mechanisms. Nature reviews. Neuroscience 8(1):57-69. https://doi.org/10.1038/nrn2038

77. McManus RM, Heneka MT (2017) Role of neuroinflammation in neurodegeneration: new insights. Alzheimers Res Ther 9(1):14. https://doi.org/10.1186/s13195-017-0241-2

78. Pennington S, Snell K, Lee M, Walker R (2010) The cause of death in idiopathic Parkinson's disease. Parkinsonism Relat Disord 16(7):434-437

79. Leopold NA, Kagel MC (1997) Laryngeal deglutition movement in Parkinson's disease. Neurology 48(2):373-375

80. Curtis JA, Molfenter S, Troche MS (2020) Predictors of residue and airway invasion in Parkinson's disease. Dysphagia 35(2): 220-230

81. Prasad S, Holla VV, Neeraja K, Surisetti BK, Kamble N, Yadav R, Pal PK (2020) Parkinson's disease and COVID-19: perceptions and implications in patients and caregivers. Mov Disord 35(6): 912-914

82. Weyand CM, Goronzy JJ (2016) Aging of the immune system. Mechanisms and therapeutic targets. Ann Am Thoracic Soc 13(Supplement 5):S422-S428

83. Brugger F, Erro R, Balint B, Kägi G, Barone P, Bhatia KP (2015) Why is there motor deterioration in Parkinson's disease during systemic infections-a hypothetical view. npj. Parkinson's Dis 1(1):1-5

84. Pavel A, Murray DK, Stoessl AJ (2020) COVID-19 and selective vulnerability to Parkinson's disease. Lancet Neurol 19(9):719. https://doi.org/10.1016/S1474-4422(20)30269-6

85. Jang H, Boltz D, Sturm-Ramirez K, Shepherd KR, Jiao Y, Webster R, Smeyne RJ (2009) Highly pathogenic H5N1 influenza virus can enter the central nervous system and induce neuroinflammation and neurodegeneration. Proc Natl Acad Sci U S A 106(33):14063-14068. https://doi.org/10.1073/pnas.0900096106

86. Helmich RC, Bloem BR (2020) The impact of the COVID-19 pandemic on Parkinson's disease: hidden sorrows and emerging opportunities. J Parkinsons Dis 10(2):351

87. Hemmerle AM, Herman JP, Seroogy KB (2012) Stress, depression and Parkinson's disease. Exp Neurol 233(1):79-86

88. Zach H, Dirkx MF, Pasman JW, Bloem BR, Helmich RC (2017) Cognitive stress reduces the effect of levodopa on Parkinson's resting tremor. CNS Neurosci Therapeut 23(3):209-215

89. Markus HS, Brainin M (2020) COVID-19 and stroke - a global World Stroke Organization perspective. Int J Stroke 15(4):361364

90. Liu R, Zhao J, Fisher M (2020) The global impact of COVID-19 on acute stroke care. CNS Neurosci Therapeut

91. Mehta P, DF MA, Brown M, Sanchez E, Tattersall RS, Manson JJ, Collaboration HAS (2020) COVID-19: consider cytokine storm syndromes and immunosuppression. Lancet (London, England) 395(10229):1033

92. Arima H, Huang Y, Wang JG, Heeley E, Delcourt C, Parsons M, Li Q, Neal B et al (2012) Earlier blood pressure-lowering and greater attenuation of hematoma growth in acute intracerebral hemorrhage: INTERACT pilot phase. Stroke 43(8):2236-2238 
93. Seabra C, Silva B, Fagundes V, Rocha J, Nogueira L, Mesquita M (2020) Should the management of embolic stroke in the elderly be changed if they also have COVID-19. Eur J Case Rep Int Med 7(6)

94. Zhai P, Ding Y, Li Y (2020) The impact of COVID-19 on ischemic stroke: a case report.

95. Avula A, Nalleballe K, Narula N, Sapozhnikov S, Dandu V, Toom S, Glaser A, Elsayegh D (1920) Journal Pre-proofs.

96. Abdulkadir T, ÜNLÜBAȘ Y, ALEMDAR M, AKYÜZ E (2020) Coexistence of COVID-19 and acute ischemic stroke report of four cases. J Clin Neurosci

97. Oxley TJ, Mocco J, Majidi S, Kellner CP, Shoirah H, Singh IP et al (2020) Large-vessel stroke as a presenting feature of Covid19 in the young. N Engl J Med 382(20):e60

98. Grau A, Buggle F, Becher H, Zimmermann E, Spiel M, Fent T, Maiwald M, Werle E et al (1998) Recent bacterial and viral infection is a risk factor for cerebrovascular ischemia: clinical and biochemical studies. Neurology 50(1):196-203

99. Trejo-Gabriel-Galán J (2020) Stroke as a complication and prognostic factor of COVID-19. Neurologia (Barcelona, Spain).

100. Gilden D, Cohrs RJ, Mahalingam R, Nagel MA (2009) Varicella zoster virus vasculopathies: diverse clinical manifestations, laboratory features, pathogenesis, and treatment. Lancet Neurol 8(8): 731-740

101. Elkind MS (2007) Why now? Moving from stroke risk factors to stroke triggers. Curr Opin Neurol 20(1):51-57

102. Huang C, Wang Y, Li X, Ren L, Zhao J, Hu Y, Zhang L, Fan G et al (2020) Clinical features of patients infected with 2019 novel coronavirus in Wuhan, China. Lancet 395(10223):497-506

103. Arachchillage DR, Laffan M (2020) Abnormal coagulation parameters are associated with poor prognosis in patients with novel coronavirus pneumonia. J Thromb Haemost 18(5):1233-1234

104. Kaushik P, Kaushik M, Parveen S, Tabassum H, Parvez S (2020) Cross-talk between key players in patients with COVID-19 and ischemic stroke: a review on neurobiological insight of the pandemic. Mol Neurobiol 57(12):4921-4928. https://doi.org/10. 1007/s12035-020-02072-4

105. Huber G, Schuster F, Raasch W (2017) Brain renin-angiotensin system in the pathophysiology of cardiovascular diseases. Pharmacological research, 125(Pt A), 72-90. https://doi.org/10. 1016/j.phrs.2017.06.016

106. Mehta P, McAuley DF, Brown M, Sanchez E, Tattersall RS, Manson JJ, HLH Across Speciality Collaboration, UK (2020) COVID-19: consider cytokine storm syndromes and immunosuppression. Lancet (London, England) 395(10229):1033-1034. https://doi.org/10.1016/S0140-6736(20)30628-0

107. Sylaja P, Srivastava MP, Shah S, Bhatia R, Khurana D, Sharma A, Pandian JD, Kalia K et al (2020) The SARS-CoV-2/COVID-19 pandemic and challenges in stroke care in India. Annals of the New York Academy of Sciences

108. Wang D, Hu B, Hu C, Zhu F, Liu X, Zhang J, Wang B, Xiang H et al (2020) Clinical characteristics of 138 hospitalized patients with 2019 novel coronavirus-infected pneumonia in Wuhan, China. Jama 323(11):1061-1069

109. Algahtani H, Subahi A, Shirah B (2016) Neurological complications of Middle East respiratory syndrome coronavirus: a report of two cases and review of the literature. Case Rep Neurol Med 2016

110. Guidon AC, Amato AA (2020) COVID-19 and neuromuscular disorders. Neurology 94(22):959-969

111. Dimachkie MM, Barohn RJ, Katz J (2013) Multifocal motor neuropathy, multifocal acquired demyelinating sensory and motor neuropathy, and other chronic acquired demyelinating polyneuropathy variants. Neurol Clin 31(2):533-555

112. World Health Organization. (2020). Protocol for assessment of potential risk factors for coronavirus disease 2019 (COVID-19) among health workers in a health care setting, 23 March 2020
(No. WHO/2019-nCoV/HCW_risk_factors_protocol/2020.3). World Health Organization.

113. World Health Organization. (2020). The first few X cases and contacts (FFX) investigation protocol for coronavirus disease 2019 (COVID-19), 23 February 2020 (No. WHO/2019-nCoV/ FFXprotocol/2020.3). World Health Organization.

114. Ahmed MU, Hanif M, Ali MJ, Haider MA, Kherani D, Memon GM, Karim AH, Sattar A (2020) Neurological manifestations of COVID-19 (SARS-CoV-2): a review. Front Neurol 11:518

115. Yan Q, Wang B, Gong D, Luo C, Zhao W, Shen J, Shi Q, Jin S, Zhang L, You Z (2020) COVID-19 chest CT image segmentation-a deep convolutional neural network solution. arXiv preprint arXiv:200410987.

116. Rele S (2020) Emerging outbreaks and epidemic threats: the practicality and limitations in the development and manufacturing of treatments for Coronavirus (COVID-19). Polymorphism 4:45-52

117. Fueyo-Casado A (2012) Miscellanea: antihistamines, dapsone, antimalarials. Dermatol Treat 403

118. Margeta M (2020) Autophagy defects in skeletal myopathies.

119. Hu TY, Frieman M, Wolfram J (2020) Insights from nanomedicine into chloroquine efficacy against COVID-19. Nat Nanotechnol 15(4):247-249

120. Singh R, Vijayan V (2020) Chloroquine: a potential drug in the COVID-19 scenario. Trans Ind Nat Acad Eng:1-12

121. Siddiqui AJ, Jahan S, Ashraf SA, Alreshidi M, Ashraf MS, Patel $\mathrm{M}$ et al (2020) Current status and strategic possibilities on potential use of combinational drug therapy against COVID-19 caused by SARS-CoV-2. J Biomol Struct Dyn:1-14

122. Kundu CN, Das S, Nayak A, Satapathy SR, Das D, Siddharth S (2015) Anti-malarials are anti-cancers and vice versa-one arrow two sparrows. Acta Trop 149:113-127

123. Ferner, R. E., \& Aronson, J. K. (2020). Chloroquine and hydroxychloroquine in covid-19.

124. Mubagwa K (2020) Cardiac effects and toxicity of chloroquine: a short update. Int J Antimicrob Agents:106057-106057

125. Rockx B, Baas T, Zornetzer GA, Haagmans B, Sheahan T, Frieman M, Dyer MD, Teal TH et al (2009) Early upregulation of acute respiratory distress syndrome-associated cytokines promotes lethal disease in an aged-mouse model of severe acute respiratory syndrome coronavirus infection. J Virol 83(14):70627074

126. Illei GG, Shirota Y, Yarboro CH, Daruwalla J, Tackey E, Takada K, Fleisher T, Balow JE et al (2010) Tocilizumab in systemic lupus erythematosus: data on safety, preliminary efficacy, and impact on circulating plasma cells from an open-label phase I dosage-escalation study. Arthritis Rheum 62(2):542-552

127. Moutsopoulos HM, Zampeli E, Vlachoyiannopoulos PG (2018) Medications, therapeutic modalities, and regimens used in the management of rheumatic diseases. In: Rheumatology in questions. Springer, pp. 153-175

128. Omambia OA (2020) A research proposal on the diagnosis, clinical classification and therapeutic regimina for timely elimination of sars-cov- $2, \beta$-cov disease causing virus.

129. Santhanam J (2020) Dr. Jayashree Santhanam. Homoeopathy and covid-19. Int J Homoeopathic Sci 4(2):85-91

130. Zhang L, Pang R, Xue X, Bao J, Ye S, Dai Y, Zheng Y, Fu Q et al (2020) Anti-SARS-CoV-2 virus antibody levels in convalescent plasma of six donors who have recovered from COVID-19. Aging (Albany NY) 12(8):6536

131. Baldari S, Di Rocco G, Piccoli M, Pozzobon M, Muraca M, Toietta G (2017) Challenges and strategies for improving the regenerative effects of mesenchymal stromal cell-based therapies. Int J Mol Sci 18(10):2087

132. Raza SS, Khan MA (2020) Mesenchymal stem cells: a new front emerge in COVID19 treatment: mesenchymal stem cells therapy for SARS-CoV2 viral infection. Cytotherapy. 
133. Marolt Presen D, Traweger A, Gimona M, Redl H (2019) Mesenchymal stromal/stem cell-based bone regeneration therapies: from cell transplantation and tissue engineering to therapeutic secretomes and extracellular vesicles. Front Bioeng Biotechnol $7: 352$

134. Sahu KK, Siddiqui AD, Cerny J (2020) Mesenchymal stem cells in COVID-19: a journey from bench to bedside. Lab Med

135. Singh VK, Mishra A, Singh S, Kumar P, Singh M, Jagannath C, Khan A (2020) Emerging prevention and treatment strategies to control COVID-19. Pathogens 9(6):501

136. Sun X, Wang T, Cai D, Hu Z, Liao H, Zhi L, Wei H, Zhang Z et al (2020) Cytokine storm intervention in the early stages of COVID19 pneumonia. Cytokine Growth Factor Rev

137. Alzahrani FA, Saadeldin IM, Ahmad A, Kumar D, Azhar EI, Siddiqui AJ, Jahan S (2020) The potential use of mesenchymal stem cells and their derived exosomes as immunomodulatory agents for COVID-19 patients. Stem Cells Int

138. Metcalfe AD, Ferguson MW (2007) Tissue engineering of replacement skin: the crossroads of biomaterials, wound healing, embryonic development, stem cells and regeneration. J R Soc Interface 4(14): 413-437

139. Thanunchai M, Hongeng S, Thitithanyanont A (2015, 2015) Mesenchymal stromal cells and viral infection. Stem Cells Int

140. Rogers CJ, Harman RJ, Bunnell BA, Schreiber MA, Xiang C, Wang F-S, Santidrian AF, Minev BR (2020) Rationale for the clinical use of adipose-derived mesenchymal stem cells for COVID-19 patients. J Transl Med 18:1-19

141. Muraca M, Pessina A, Pozzobon M, Dominici M, Galderisi U, Lazzari L, Parolini O, Lucarelli E et al (2020) Mesenchymal stromal cells and their secreted extracellular vesicles as therapeutic tools for COVID-19 pneumonia. J Control Release

142. Hombach A, Hombach A, Abken H (2010) Adoptive immunotherapy with genetically engineered $T$ cells: modification of the IgG1 Fc 'spacer'domain in the extracellular moiety of chimeric antigen receptors avoids 'off-target'activation and unintended initiation of an innate immune response. Gene Ther 17(10):12061213

143. Liu B, Zhang W, Zhang H (2019) Development of CAR-T cells for long-term eradication and surveillance of HIV-1 reservoir. Curr Opin Virol 38:21-30

144. Chen X, Han J, Chu J, Zhang L, Zhang J, Chen C, Chen L, Wang $Y$ et al (2016) A combinational therapy of EGFR-CAR NK cells and oncolytic herpes simplex virus 1 for breast cancer brain metastases. Oncotarget 7(19): 27764

145. Jacoby E, Shahani SA, Shah NN (2019) Updates on CAR T-cell therapy in B-cell malignancies. Immunol Rev 290(1):39-59

146. Bertoletti A, Tan AT (2020) HBV as a target for CAR or TCR-T cell therapy. Curr Opin Immunol 66:35-41
147. Harrison RP, Zylberberg E, Ellison S, Levine BL (2019) Chimeric antigen receptor-T cell therapy manufacturing: modelling the effect of offshore production on aggregate cost of goods. Cytotherapy 21(2):224-233

148. Caruso HG, Heimberger AB, Cooper LJ (2019) Steering CAR T cells to distinguish friend from foe. Oncoimmunology $8(10)$ : e1271857

149. Monteil V, Kwon H, Prado P, Hagelkrüys A, Wimmer RA, Stahl M, Leopoldi A, Garreta E et al (2020) Inhibition of SARS-CoV-2 infections in engineered human tissues using clinical-grade soluble human ACE2. Cell.

150. Sarkar A, Maulik U (2020) Vaccines and treatment strategies for SARS-COV-2.

151. Shrimp JH, Kales SC, Sanderson PE, Simeonov A, Shen M, Hall MD (2020) An enzymatic TMPRSS2 assay for assessment of clinical candidates and discovery of inhibitors as potential treatment of COVID-19. BioRxiv.

152. Siddiqui AJ, Danciu C, Ashraf SA, Moin A, Singh R, Alreshidi M et al (2020) Plants-derived biomolecules as potent antiviral phytomedicines: new insights on ethnobotanical evidences against coronaviruses. Plants 9(9):1244

153. Wood JM, Robertson JS (2004) From lethal virus to life-saving vaccine: developing inactivated vaccines for pandemic influenza. Nat Rev Microbiol 2(10):842-847

154. Lurie N, Saville M, Hatchett R, Halton J (2020) Developing Covid-19 vaccines at pandemic speed. N Engl J Med 382(21): 1969-1973

155. Cohen J (2020) Vaccine designers take first shots at COVID-19. American Association for the Advancement of Science

156. Chen Y, Liu Q, Guo D (2020) Emerging coronaviruses: genome structure, replication, and pathogenesis. J Med Virol 92(4):418423

157. Sun R, Skeiky YA, Izzo A, Dheenadhayalan V, Imam Z, Penn E, Stagliano K, Haddock S et al (2009) Novel recombinant BCG expressing perfringolysin $\mathrm{O}$ and the over-expression of key immunodominant antigens; pre-clinical characterization, safety and protection against challenge with Mycobacterium tuberculosis. Vaccine 27(33):4412-4423

158. Liu Z, Xiao X, Wei X, Li J, Yang J, Tan H et al (2020) Composition and divergence of coronavirus spike proteins and host ACE2 receptors predict potential intermediate hosts of SARS-CoV-2. J Med Virol 92(6):595-601

Publisher's Note Springer Nature remains neutral with regard to jurisdictional claims in published maps and institutional affiliations. 